\title{
Applying multivariate-fractionally integrated volatility analysis on emerging market bond portfolios
}

\author{
Mustafa Demirel ${ }^{1,2}$ and Gazanfer Unal ${ }^{3^{*}}$
}

\author{
* Correspondence: gazanferunal@ \\ gmail.com \\ ${ }^{3}$ Administrative Sciences, Bahcesehir \\ University, 34349 Istanbul, Turkey \\ Full list of author information is \\ available at the end of the article
}

\begin{abstract}
This study examines emerging market (EM) local bonds from a portfolio risk perspective and suggests methodologies for risk evaluation, on which the literature is limited. Despite the growth of EM bond funds in recent years, comprehensive studies regarding this industry have been scarce. In light of this, 203 different local bonds of EM countries - Indonesia, Brazil, India, South Africa, Mexico, and Turkeyare elaborated in terms of return, volatility, and cross-correlation features. This study focuses on an untouched field - long memory properties - and the application of fractional models to EM bond portfolios. Based on the outcomes of a dynamic conditional correlation and fractionally integrated generalized autoregressive conditional heteroscedasticity approach and related value at risk analysis, the study finds that fractional models are useful tools for risk management, as they deliver satisfactory empirical results for several static and dynamic versions of EM bond portfolios.
\end{abstract}

\section{Introduction and literature review}

In the last decade, surging capital flows to emerging market (EM) bonds and the popularity of EM funds have made research in this field valuable. In recent years, due to extraordinary shifts in the monetary policies of developed market (DM) and countryspecific macroeconomic developments, EM currencies and interest rates have fluctuated sharply. Although the composition of EM bond funds is heterogeneous because the countries involved have different economic and market structures, these countries' asset prices are correlated to each other. Unhedged bond portfolios that are affected by both currencies and interest rates have suffered, and having an effective risk management strategy has become more critical.

The literature on risk analysis of EM fixed income has been limited and scattered. Early research mostly focused on the risk-reward profile and showed the diversification benefits of EM bonds, along with other asset classes (Burik and Ennis 1990, Erb et al. 1999, etc.). Similarly, research on systemic risk, risk transmission, or financial network touched on EM bonds as part of the whole investment universe (see Kou

(c) The Author(s). 2020, corrected publication 2020. Open Access This article is licensed under a Creative Commons Attribution 4.0 International License, which permits use, sharing, adaptation, distribution and reproduction in any medium or format, as long as you give appropriate credit to the original author(s) and the source, provide a link to the Creative Commons licence, and indicate if changes were made. The images or other third party material in this article are included in the article's Creative Commons licence, unless indicated otherwise in a credit line to the material. If material is not included in the article's Creative Commons licence and your intended use is not permitted by statutory regulation or exceeds the permitted use, you will need to obtain permission directly from the copyright holder. To view a copy of this licence, visit http://creativecommons.org/licenses/by/4.0/. 
et al. 2019). Some others considered immunization strategies in this area (see Ortobelli and Sebastiano 2018, etc.).

In the extensive literature, value at risk (VaR) and related volatility modeling are the prominent risk management concepts that have been applied frequently. Nevertheless, applications of this approach to EM bond portfolios are insufficient. Therefore, referring to studies on other asset classes, especially those dealing with the developed market bonds, is the only plausible way.

Guo et al. (2007) applied quantile VaR to U.S. corporate bond indices and incorporated treasury interest rates as information variables. Although using these information variables was beneficial, the estimated confidence intervals for VaRs were wide, thus downgrading the applicability of the model. Tu and Chen (2018) evaluated U.S. bond indices with a factor-based approach. VaR estimations of the study present that market shocks (not macroeconomic developments) primarily cause the variations. Vlaar (2000) compared the out of sample performances of volatility models with different distributions and stated that generalized autoregressive conditional heteroscedasticity (GARC $\mathrm{H})$ models deliver the best results under a normal distribution assumption. Yet, the analysis considered only the univariate volatilities in Dutch bond portfolios.

In the literature, there are also other advanced techniques to consider such as the novel Markov-switching (MS) models. Although EM bonds have not been part of the scope, the MS model framework has been applied to fixed income markets, as well as other asset classes, in recent years (Escobar et al. 2017, Elliott and Nishide 2014, Dimpfl and Peter 2016, Guidolin et al. 2014, Hevia et al. 2015, Kim et al. 2019, etc.). Business cycles in long-term data series and bull and bear markets are the usual concepts for the MS models. As such, the necessity of separating the impacts of the global financial crisis has been one of the motivations behind the recent popularity of MS models.

Meanwhile, in fractal (self-similar) structures, MS models have some drawbacks in terms of capturing the long memory because assumed regime changes reduce the persistence impact. Furthermore, in the literature, most studies have focused on univariate or bivariate time series with two-state models. In the case of multivariate data series, with time variant probabilities and possible multi-state model selection, the process becomes cumbersome, and with too many explanatory variables, the inference could become complicated.

In the data series of bonds, especially in the volatilities, fractal features can be observed. Apart from the pricing dynamics of the bonds, as the coupon payments or the accrued interests slowly change over time, they become integrated in the returns. Under these conditions, regarding volatility, we evaluate based on a relatively new concept, that is, fractional modeling. The preliminary analysis justifies this type of approach. It considers the fractal (self-similar) features of datasets and quantifies the persistence of shocks in financial markets. The volatility model, fractionally integrated GARCH (FIGARCH), was proposed by Baillie (1996) after the introduction of the mean model alternative auto-regressive fractionally integrated moving average (ARFIMA; see Granger and Joyeux 1980 and Hosking 1981).

The FIGARCH model focuses on the hyperbolic decay of the impacts of previous innovations in the volatility. It extends the application of the integrated GARCH model (IGARCH), thereby providing an opportunity to determine the true level of the hyperbolic decay at the impact of the previous shocks. Unlike regime-switching models, the 
number of explanatory variables increases slightly, which makes it easy to incorporate and interpret. Subsequently, various models have been proposed in this "fractional" framework. In this field, fractionally integrated exponential GARCH (FIEGARCH), hyperbolic GARCH (HYGARCH) and fractionally integrated asymmetric power ARCH (FIAPARCH) are some examples that cover additional features of volatility such as leverage or asymmetry.

Tsung and Shieh (2007) conducted a VaR analysis for Treasury bond futures with fractional volatility models and showed the superior performance of FIGARCH under normal, Student-t, and skewed Student-t distributions. Martinez et al. (2016) used fluctuation analysis (i.e., detrended fluctuation analysis; DFA) to investigate the long memory in European stock and bond markets. The major finding of the study is the fractal structure of corporate bonds, which implies that modeling the data has to consider long memory properties. In similar studies, Zunino et al. (2015) and Ferreira (2018) presented evidence of long-range dependence in the returns of various sovereign and corporate bond markets as a factor of market inefficiency. Cotter (2004) applied several GARCH type models to U.K. financial markets. He stated that the highest level of long range-dependence is observed in bond futures.

On EM bonds, as one of a few examples, Jung and Kim (2012) analyzed highfrequency data of Korean Treasury bond futures and concluded that the return volatility of this asset class has persistence. As another example, Mendoza (2005) successfully revealed long memory features in Latin American sovereign bonds. Although its application is rare in fixed income assets, the efficiency of fractional volatility modeling has been demonstrated for other asset classes several times. (See Ding et al. 1993, Lardic and Mignon 1999, Serletis and Andreadis 2004, Jin and Frechette 2004, Baillie and Morana 2007, Tabak and Cajueiro 2007, Kasman 2009, Ksaier and Cristiani-D'ornano 2010, Manap and Kassim 2011, Chang et al. 2012, Wang 2013, Sensoy and Sobaci 2014, etc.)

For the second point, we deploy the dynamic conditional correlation (DCC) model of Engle (2002) to examine the co-movements. Dynamic copulas or wavelet transformations are the other advanced techniques that have been applied in recent literature. Copulas focus on the interdependence of individual distributions and the linkage between individual and multivariate distributions; they have various forms including parametric and/or regime switching. Nevertheless, as copulas deal with distributions, solo applications can be used for tail dependence, risk budgeting, and related tools such as option pricing. Moreover, since model alternatives are relatively limited for multivariate cases (Archimedean and elliptical) and having too many parameter estimations is burdensome, most of the literature have focused on bivariate cases. Furthermore, optimal parametric copula model selection (related goodness-of-fit tests), which affects tail dependence, is another discussion point (see also Weiß 2013). Recent applications in the fixed income market have usually been through developed markets or credit risks (see Kim et al. 2020, Yang et al. 2020, Chao and Zou 2018, Otani and Imai 2018, Bekiros et al. 2018, Benlagha 2014, Chen et al. 2014 etc.)

The other technique, wavelet transformation, also drew attention, in recent years. Especially in stock markets and commodities, the wavelet method has been frequently applied to investigate interdependence and coherence. However, there has been limited application on EM bonds (Najeeb et al. 2017). As in the case of copulas, wavelet 
transformation needs additional model for forecasting. Application, extracting, and model selection needs intensive computation for a meaningful analysis. Moreover, in multivariate cases, as the number of data series increases, the process becomes highly complicated. Gulerce and Unal (2016) reached, at most, five different time series for coherence of the analysis.

Meanwhile, our selection of the DCC model is not only useful for risk budgeting but also easy to implement for forecasting and portfolio optimization. Furthermore, unlike the aforementioned approaches, under this method, estimation results are easy to comprehend.

Most of the existing DCC applications to bonds are specific to regional submarkets and tackle the concept of market integration. Applying the DCC-GARCH model, Tsukuda et al. (2017) revealed that integration within the Asian bond market is shallow. Champagne et al. (2017) showed strong market interdependence between the U.S. and Canadian corporate bond markets. Kenourgios et al. (2013) investigated the contagion effects of the global financial crisis (GFC) by applying an asymmetric generalized DCC (AG-DCC) model to Brazilian long-term bond indices, along with other asset classes, and found contagion links of the bonds with U.S. stocks, real estate, and commodities. In a similar framework, Kenourgios and Padhi (2012) covered the bond markets of a wide range of EM countries and found the co-integration levels and diversification benefits of EM bonds during wellknown crises, including the late 1990s. By applying DCC-GARCH models, Sclip et al. (2016) and Bhuiyan et al. (2018) revealed the diversification benefits of sukuks (Islamic bonds) within given samples (see also Goeij 2004, Kenourgios et al. 2011, Celik 2012, Christiansen 2010, Benlagha 2014, Bessler et al. 2016, and Fang et al. 2018).

Regarding other asset classes of EM, Dimitriou et al. (2013) applied a DCC-FIAPAR $\mathrm{CH}$ model to Brazil, Russia, India, China and South Africa stock markets and showed an increasing contagion effect during the GFC. Other studies revealed the superior performance of multivariate applications regarding volatility persistence properties (e.g., Engle and Colacito 2006; Harris and Nguyen 2013; Selmi and Hachicha 2015).

To summarize, there has been a literature gap in covering EM bonds from the portfolio management standpoint. Furthermore, despite findings of the long memory feature of bond markets (and many other markets such as stocks and commodities) it has not been taken into account in this framework. This study contributes by filling this gap. Specifically, it covers EM local bonds (as well as the currencies) of a wide range of countries and derives satisfactory model outcomes.

Because this study targets funds or portfolio investments, it deals with institutional investors. For the retail side, there are other concepts to deal with (see Wen et al. 2019). As another assumption, this study leaves out matters related to cost, as further analysis may be required regarding cost efficiency. Particularly for the credit-risk side, cost sensitive analysis may affect the strategies (see Wang et al. 2020).

This study mainly presents risk management tools that are versatile and comprehensive for EM local bond portfolios. For this purpose, modern time series approaches that consider fractal data structures and correlation dynamics are sought. The study primarily focuses on three aspects: return-volatility dynamics, correlation features, and VaR performances. 
The remainder of this paper is organized as follows. The next section explains the compilation method of the bonds and the construction of the proxy time series that are suitable for evaluating the portfolios. Section 3 briefly covers specific long memory models and the DCC approach to be employed in the empirical analyses. In Section 4, together with a basic analysis of the data, the results of four different multivariate models are presented. In this section, using the selected model, out-of-sample VaR performances are examined for static and dynamic portfolio samples, including portfolio optimization. In Section 5, inferences of the analyses are compiled and the main findings of this study are presented.

\section{Data}

For the portfolio construction, the local bonds of Indonesia, Brazil, India, South Africa, Mexico, and Turkey's treasuries are examined. All bonds traded in the last 10 years are considered, and a total of 203 different bonds are selected. Every selected bond is either in the discounted form or has a fixed coupon payment. The selected bonds are in their local currencies.

The bond selection is based on maturity and liquidity criteria. Bonds that have maturities close to either 2 or 10 years are filtered. Bonds that are not liquid and not traded every working day are omitted. Coupon payments are assumed to be reinvested in the same bond. As time passes, when a bond in the portfolio fails to match the criteria, it is changed with a new one.

Although, daily prices of the selected bonds are recorded, the returns are compounded on a weekly basis. In financial markets, determination of the data frequency can affect the results of empirical analysis (see Narayan and Sharma 2015; Narayan et al. 2015). Nevertheless, as in the case of security selection, the main motivation for using weekly returns is to reflect the performance of an EM bond portfolio, that is, practicality. Because EM bonds are usually traded in over-the-counter platforms, and there are primary dealing advantages, higher frequencies, like daily data, are prone to distortions. Sometimes, liquidity is scarce with few transactions; as such, observed noises are cleaned only the following sessions. Although, these kinds of noises are disregarded by real investors, they can distort our volatility analysis. Furthermore, as we focus on portfolio analysis, applying portfolio weights to daily returns may not be realistic because in the real world it can be difficult and costly to rebalance EM bond portfolios on a daily basis. By contrast, lower frequencies, like on monthly basis, can lower the number of observations and lower the degrees of freedom in the analysis. Because available data are limited in EM, the number of out-of sample observations can be too small to perform a reliable VaR analysis. Again, regarding a sensible rebalancing period in the portfolios, using weekly data for analyses is considered more appropriate than using lower frequencies.

The local currency returns of bonds are converted to U.S. dollar returns based on the exchange rates of USD/IDR, USD/BRL, USD/IND, USD/ZAR, USD/MXN, and USD/ TRY, at the respective dates of the transactions. The pricing source for the bonds, as well as the currencies, is Bloomberg, and daily closing prices are used. Portfolio data are constructed to reflect the structure of USD-denominated EM local bond funds.

Bonds are grouped as short-term (ST) and long-term (LT) bonds to construct two different portfolios. In the literature or in the industry, there is no direct definition of 
Table 1 Basic features of the selected bonds

\begin{tabular}{lllll}
\hline Selected Markets & Average Yield (Cmpd.) & Average Duration (Yrs.) & Base Currency & Coupon Type \\
\hline Short-Term Bonds & & & & \\
Indonesia & 7.12 & 1.75 & IDR & Fixed \\
Brazil & 11.31 & 1.81 & BRL & Fixed \\
India & 7.32 & 1.81 & INR & Fixed \\
South Africa & 7.11 & 1.73 & SA & Fixed \\
Mexico & 5.32 & 1.75 & MXN & Fixed \\
Turkey & 9.25 & 1.50 & TRY & Fixed \\
Long-Term Bonds & & & & \\
Indonesia & 8.23 & 6.82 & IDR & Fixed \\
Brazil & 12.08 & 5.57 & BRL & Fixed \\
India & 7.77 & 6.79 & INR & Fixed \\
South Africa & 8.36 & 6.87 & SA & Fixed \\
Mexico & 6.73 & 7.02 & MXN & Fixed \\
Turkey & 9.5 & 5.59 & TRY & Fixed \\
\hline
\end{tabular}

short-term or long-term bonds. Meanwhile, to construct proxy portfolios, the holdings or classifications of available developed market funds are useful guides. In the market, bonds with less than five-year maturity (or particularly, 1-3 year maturity) are conventionally accepted as short-term bonds. ${ }^{1}$ For long-term bonds, the interval is much wider: bonds with maturities (durations) of more than 10 years (7 years) are evaluated as long-term bonds in the major indices or funds in Europe and the United States. ${ }^{2}$

Under these conditions, it is plausible to assign bonds that have close to a two-year maturity (approximately 1.7 years duration) to the short-term bond portfolio. For the long-term bond portfolio, bonds with maturities (approximate durations) close to 10 years (6.5 years) are chosen. The duration of the long-term bond portfolio can be evaluated with a little bit shorter maturity, but for some EMs such as in Brazil and Turkey there is an insufficient number of available long-term securities.

The portfolio data cover the period January 1, 2008 to August 31, 2018 and consist of 2784 observations. A weekly rebalancing is assumed for the portfolios. The ISIN (International Securities Identification Number) codes of the selected bonds are listed in the Appendix.

In Table 1, the average duration of Turkish bonds is up to 1 year shorter than the other bonds in the long-term bond portfolio because before 2011, the Turkish treasury did not issue long term bonds. Moreover, as can be observed below, the average yields of Mexican bonds are below average, as Brazilian and Turkish bonds have exceptionally high yields.

\section{Methodology}

In the data sample, every return series has periods that are riskier than the others (see Figures 1 and 2 in Appendix). In other words, there exist periods of sharp movements and small changes. Further statistical analyses of the data are shown in the next section.

\footnotetext{
${ }^{1}$ See the fund classification of the European Fund and Asset Management Association (EFAMA) at www. efama.org and the fund databases such as www.etfdb.com.

${ }^{2}$ See Vanguard Long-Term Bond Index (VBLTX) and Fidelity Long-Term Treasury Bond Index (FNBGX).
} 
However, the marks of volatility clustering and autocorrelation (also of the squared residuals) have to be considered to ensure the assumptions of classical linear regression models. Since in the case of conditional heteroskedasticity, the efficiency rule is not ensured, checks on the parameter estimations are unreliable. In other words, in such cases, linear regression estimations will still be unbiased but less certain. Variations in the estimations are high, and standard errors are biased, which can lead to dealing with statistically insignificant coefficients. Conditional heteroscedasticity can lead to wrong hypothesis testing if the null hypothesis is mistakenly rejected (see Gauss-Markov theorem; Engle 1982 and the assumptions of the classical linear regression model). Considering related findings in the literature, the estimations are performed by applying ARIMA and ARFIMA mean models, together with GARCH and FIGARCH volatility models.

Moreover, each return series has distinctive behaviors: periods of jumps and calms are different for each country, and co-movements are not stable at first glance. Again, based on relevant literature, a multivariate model is applied with a dynamic conditional correlation approach.

First, for the return estimation of each asset, the ARIMA method is defined as follows:

$$
a(L)(1-L)^{D}\left(y_{t}-c\right)=b(L) u_{t}
$$

where $L$ is the lag operator with $a(L)=1-a_{1} L^{1}-\ldots-a_{p} L^{p} ; b(L)=1+b_{1} L^{1}+\ldots+b_{q} L^{q} ; D$ is a positive integer; $u_{t}=\sigma_{t} e_{t} ; e_{t} \sim i . i . d$. $f\left(\right.$.) assuming $N(0,1)$; and $\sigma_{t}^{2}$ is the variance (see Box and Jenkins 1976).

The ARFIMA model introduces fractional integration on the conditional mean model to measure the long memory dependence of time series. Furthermore, ARFIMA (p,D,q) is a generalized form of ARIMA, where the integration does not have to be a positive integer. The model expression is as follows:

$$
a(L)(1-L)^{D}\left(y_{t}-c\right)=b(L) u_{t}
$$

where $a(L)$ and $b(L)$ are usual $\mathrm{AR}(\mathrm{p})$ and $\mathrm{MA}(\mathrm{q})$ expressions, and all the roots are in the unit circle. $D$ is the fractional differencing parameter that defines the fractional differencing filter as $(1-L)^{D}=\frac{(j-D-1) !}{j !(-D-1) !} L^{j}$, and $j=1,2,3 \ldots$ (see Granger and Joyeux 1980; Hosking 1981).

Regarding volatility, univariate volatilities and cross-correlations are to be estimated, as the portfolio variance is defined as follows:

$$
\sigma_{p, t}^{2}=\sum_{i=1}^{N} \sum_{j=1}^{N} w_{i} w_{j} \sigma_{i, t} \sigma_{j, t} \rho_{i j, t},
$$

where $w_{i}$ is the weight, and $\sigma_{i, t}$ is the conditional volatility of the $i$ th asset in the portfolio at time $t$, and $\rho_{i, j, t}$ is the conditional correlation of the $i$ th asset with the $j$ th asset at time $t$ (see the modern portfolio theory or Markowitz 1952).

The GARCH model is, in general, in the following form (Bollerslev 1986):

$$
\sigma_{t}^{2}=w+\alpha(L) u_{t}^{2}+\beta(L) \sigma_{t}^{2},
$$

where $L$ is the lag operator with $\phi(L)(1-L)^{d}\left(y_{t}-\mu\right)=\theta(L) u_{t} ; \beta(L) \equiv L+\beta_{2} L^{2}+\ldots+\beta_{p} L^{p}$;

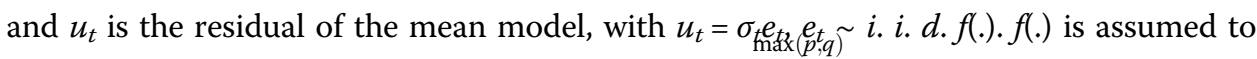
be a strong white noise process. $w>0 ; \alpha_{i} \geq 0 ; \beta_{i} \geq 0 ; \sum_{i=1}\left(\alpha_{i}+\beta_{i}\right)<1$; and 
$\alpha_{i}, \beta_{i} \equiv 0$ for $i>p$ and $j>q$ for a general $\operatorname{GARCH}(p, q)$ model.

Meanwhile, Baillie (1996) defines the FIGARCH model as follows:

$$
\phi(L)(1-L)^{d}\left(y_{t}-\mu\right)=\theta(L) u_{t},
$$

where $d$ is the fractional differencing parameter, and using its properties, the equation reduces to (see Hosking 1981):

$$
\sigma_{t}^{2}=\frac{w}{[1-\beta(L)]}+\lambda(L) u_{t}^{2}, \text { where } \lambda(L) \text { isthein finitelagoperatorwith }
$$

$\lambda(L)=\lambda_{1} L^{1}+\lambda_{2} L^{2}+\lambda_{3} L^{3} \ldots$, and the features of the fractional differencing filter are the same as in the case of ARFIMA.

To estimate the portfolio risk together with individual volatilities, contemporaneous correlations also need to be estimated. In this step, with the DCC model, pairwise correlations are modeled in a way similar to the modeling of volatilities. Let $u_{t}=r_{t}-\mu_{t}$ be the residuals vector, with $r_{t}$ as the vector of individual returns and $\mu_{t}$ as the expected returns.

In the DCC model, the covariance matrix of the residuals vector can be split as $\Sigma_{t} \equiv$ $D_{t} R_{t} D_{t}$, where $R_{t}$ is the conditional correlation matrix, and $D_{t}$ is the diagonal matrix of individual volatilities. Bollerslev (1990) defines the estimator of the constant conditional correlation as follows:

$\bar{R}=\frac{1}{T} \sum_{t=1}^{T} \eta_{t} \eta_{t}^{\prime}$, where $\eta_{t}$ is the vector of standardized residuals as in $\eta_{t}=D_{t}^{-1} u_{t}$.

The dynamic correlation generalization is similar to the GARCH approach:

$$
Q_{t}=\bar{R}+\gamma\left(\eta_{\mathrm{t}-1} \eta_{t-1}^{\prime}-\bar{R}\right)+\delta\left(Q_{t-1}-\bar{R}\right)
$$

where the elements of $Q_{t}$ are from the estimated pairwise correlations at time $t$.

The estimation of a DCC $(1,1)$ model is performed through the log-likelihood function

$$
L(\theta)=-\frac{1}{2} \sum_{t=1}^{T}\left(n \log (2 \pi)+\log \left(\left|D_{t} R_{t} D_{t}\right|\right)+r_{t}^{\prime} D_{t}^{-1} R_{t}^{-1} D_{t}^{-1} r_{t}\right)
$$

where $\theta=(\omega, \alpha, \beta, \phi, \gamma, \delta)$, and the parameters of univariate GARCH models and pairwise correlations are estimated separately (see Engle and Sheppard 2001 and Engle 2002).

\section{Analysis and results}

\section{Preliminary analysis}

For both short- and long-term bonds, Brazil's bonds have the best returns, in line with their average yields. From Table 2, regarding the means and the standard deviations, it is difficult to observe the expected risk-return relationship. For the short-term portfolio, Turkish bonds are the riskiest assets, but they do not offer the best return. For the long-term portfolio, although Indonesian bonds have the highest risk, with a maximum of $13.5 \%$ weekly loss and $1.95 \%$ standard deviation, it ranks third in terms of mean returns.

Regarding the normality checks, except for the short-term bonds of Turkey and Indonesia and the long-term bonds of South Africa, all bonds are negatively skewed. As almost all bonds are fat-tailed with high Kurtosis levels, the Jarque-Bera test results 
Table 2 Preliminary analysis of the assets

\begin{tabular}{|c|c|c|c|c|c|c|}
\hline & Indonesia ST & Brazil ST & India ST & S. Africa ST & Mexico ST & Turkey ST \\
\hline Number of Observations & 557 & 557 & 557 & 557 & 557 & 557 \\
\hline Mean & $0.156 \%$ & $0.230 \%$ & $0.134 \%$ & $0.146 \%$ & $0.111 \%$ & $0.179 \%$ \\
\hline Std. dev. & $0.46 \%$ & $0.43 \%$ & $0.22 \%$ & $0.34 \%$ & $0.23 \%$ & $0.59 \%$ \\
\hline Maximum & $3.3 \%$ & $2.2 \%$ & $1.2 \%$ & $1.8 \%$ & $1.9 \%$ & $3.4 \%$ \\
\hline Minimum & $-2.5 \%$ & $-2.9 \%$ & $-1.5 \%$ & $-2.5 \%$ & $-1.8 \%$ & $-4.6 \%$ \\
\hline Skewness & 0.24 & -1.22 & -0.52 & -0.05 & -0.18 & 1.13 \\
\hline Kurtosis & 9.65 & 10.20 & 19.69 & 9.90 & 7.84 & 13.94 \\
\hline Jarque-Bera & $2187.5^{* * *}$ & $2576.1^{* * *}$ & $9099.2^{* * *}$ & $2297.4^{* * *}$ & $1444.7^{* * *}$ & $64074^{* * *}$ \\
\hline$Q(12)$ & $43.12^{* * *}$ & $34.12^{* * *}$ & 9.18 & $40.53^{* * *}$ & $36.30^{* * *}$ & $22.03^{* *}$ \\
\hline$Q^{2}(12)$ & $633.57^{* * *}$ & $59.17^{* * *}$ & $129.21^{* * *}$ & $452.48^{* * *}$ & $283.18^{* * *}$ & $106.21^{* * *}$ \\
\hline$H$ & 0.8848 & 0.8128 & 0.7351 & 0.7106 & 0.7203 & 0.7521 \\
\hline \multicolumn{7}{|l|}{ Unit Root Tests } \\
\hline$A D F$ & $-80849^{* * *}$ & $-72705^{* * *}$ & $-70150^{* * *}$ & $-89878^{* * *}$ & $-66742^{* * *}$ & $-92934^{* * *}$ \\
\hline \multirow[t]{2}{*}{$P P$} & -468.41 & $-576.72^{* * *}$ & $-539.54^{* * *}$ & $-546.7^{* * *}$ & $-679.5^{* * *}$ & $-632.68^{* * *}$ \\
\hline & Indonesia LT & Brazil LT & India LT & S. Africa LT & Mexico LT & Turkey LT \\
\hline Number of Observations & 557 & 557 & 557 & 557 & 557 & 557 \\
\hline Mean & $0.165 \%$ & $0.251 \%$ & $0.118 \%$ & $0.167 \%$ & $0.145 \%$ & $0.124 \%$ \\
\hline Std. dev. & $1.95 \%$ & $1.65 \%$ & $0.86 \%$ & $1.27 \%$ & $1.38 \%$ & $1.25 \%$ \\
\hline Maximum & $10.8 \%$ & $8.9 \%$ & $4.5 \%$ & $7.1 \%$ & $16.7 \%$ & $5.3 \%$ \\
\hline Minimum & $-13.5 \%$ & $-7.5 \%$ & $-5.2 \%$ & $-11.4 \%$ & $-13.0 \%$ & $-8.8 \%$ \\
\hline Skewness & -0.93 & -1.37 & -0.90 & 0.07 & -0.99 & -1.33 \\
\hline Kurtosis & 8.42 & 14.21 & 13.75 & 5.55 & 13.35 & 7.07 \\
\hline Jarque-Bera & $1743.5^{* * *}$ & $4906.2^{* * *}$ & $4499.4^{* * *}$ & $722.28^{* * *}$ & $4265.5^{* * *}$ & $1335.8^{* * *}$ \\
\hline $\mathrm{Q}(12)$ & $33.71^{* * *}$ & 4.12 & $40.63^{* * *}$ & 17.23 & 13.79 & $30.74^{* *}$ \\
\hline$Q^{2}(12)$ & $136.51^{* * *}$ & $84.30^{* * *}$ & $114.86^{* * *}$ & $77.65^{* * *}$ & $51.41^{* * *}$ & $104.46^{* * *}$ \\
\hline$H$ & 0.9534 & 0.7943 & 0.7867 & 0.6683 & 0.7432 & 0.6982 \\
\hline \multicolumn{7}{|l|}{ Unit Root Tests } \\
\hline$A D F$ & $-68632^{* * *}$ & $-76801^{* * *}$ & $-76948^{* * *}$ & $-76179^{* * *}$ & $-90997^{* * *}$ & $-76642^{* * *}$ \\
\hline$P P$ & $-671.63^{* * *}$ & $-596.52^{* * *}$ & $-527.2^{* * *}$ & $-660.63^{* * *}$ & $-606.47^{* * *}$ & $-591.73^{* * *}$ \\
\hline
\end{tabular}

The Jarque-Bera tests the normality assumption of the time series with the null hypothesis of normality in the sample. $\mathrm{Q}(12)$ and $\mathrm{Q}^{2}(12)$ are the Ljung Box statistical tests for the serial correlation of returns and squared returns up to the lag 12. $H$ refers to the Hurst exponent of volaility; corresponds to the level of fractality. $H>0.5$ implies persistence. ADF and PP are augmented Dickey-Fuller test and Philips Perron unit root tests respectively. Both tests based on the lowest AIC value. *** refers to rejection of the null hypothesis at $1 \%$ significance level

reject the null hypothesis that distributions are in Gaussian form. Similarly, Figures 1 and 2 in Appendix show that distributions are fat-tailed; thus, it is more convenient to use Student t-distribution for further analysis.

The Q-statistics of the returns and squared returns also confirm the model selection process mentioned in the previous section. The tests of squared returns are all significant, which implies the existence of autoregressive conditional heteroskedasticity for all data series. This situation indicates the need for ARIMA and GARCH models.

The Hurst exponents of the volatility series are also listed in Table 2. Since the exponents are higher than 0.5 and especially for some series they are close to 1 , it can be deduced that there exist strong fractal features that imply long memory in the volatilities 
(see Mandelbrot 1977). Under these conditions, long memory models can be evaluated as proper approaches.

Augmented Dickey-Fuller and Philips-Perron tests reject the null hypothesis and show that the series are stationary and thus, are appropriate for time series modeling.

As can be seen in Appendix Fig. 1, all returns have very high volatility at the initial 100 observations. EM assets started in 2013 with solid performances. However, in May 2013, with the Fed announcement implying a policy normalization process, EM assets got under pressure. As the core rates went up, both currencies and bonds depreciated dramatically. This situation was common for almost all EMs.

However, for the rest of the observation, there is decoupling. The periods when the volatility levels have risen or declined differ from one country to another. In particular, Turkish bonds are seen to move in a distinct form at the latest part of the observation.

\section{Empirical results}

In-sample analysis

The sample data for empirical analysis is formed by the total return series of the bonds for the period January 1, 2008 to September 1, 2017. The return series of short-term bonds and long-term bonds are separated to construct the short- and long-term bond portfolios. In the tables below, the short- and long-term bonds are indicated as ST and LT, respectively. The data from September 1, 2017 to October 31, 2018 (52 weeks) are left for the out-of-sample performance analysis.

Four different time series models: DCC-ARIMA GARCH, DCC-FIGARCH, DCCARFIMA FIGARCH, and DCC-ARIMA FIGARCH are applied to the samples. Model estimations are performed with both the normal and Student's $t$ distributions. Nevertheless, only the estimations based on the Student's t-distribution are shown below. Furthermore, although not presented here, each model is tested under different conditions (samples). All test results under various conditions are evaluated to check the robustness of the models.

First, the estimations of the benchmark model, DCC-ARIMA GARCH, are presented in Table 3. In the mean model, seven out of 12 return series exhibit the features of auto-regression, as their related estimations are statistically significant. Notably, the auto-regression terms for both the short- and long-term bonds of India, South Africa, and Mexico are statistically significant. For the long-term bonds, almost all autoregression estimations are negative, and except for Brazil, there also seems to be a significant level of moving average effect.

Regarding volatility, the $\beta$ parameters are statistically significant for all series, providing clues about the memory in the volatilities. Since the $\alpha$ coefficients of the volatility modeling are statistically significant, except for the short-term bonds of Indonesia and India and the long-term bonds of Brazil, the impacts of the most recent innovations are also noteworthy.

Moreover, in the diagnostic checking, in line with the QQ-plots and the preliminary analysis of the raw data, the models based on a Student's t-distribution deliver way better information criteria (IC) and residual test results than the normal distribution for each data series. Thus, the results from the Student's t-distribution are shown in this section. In Table 3, the values of AIC (Akaike information criterion) and Bayesian IC are below - 


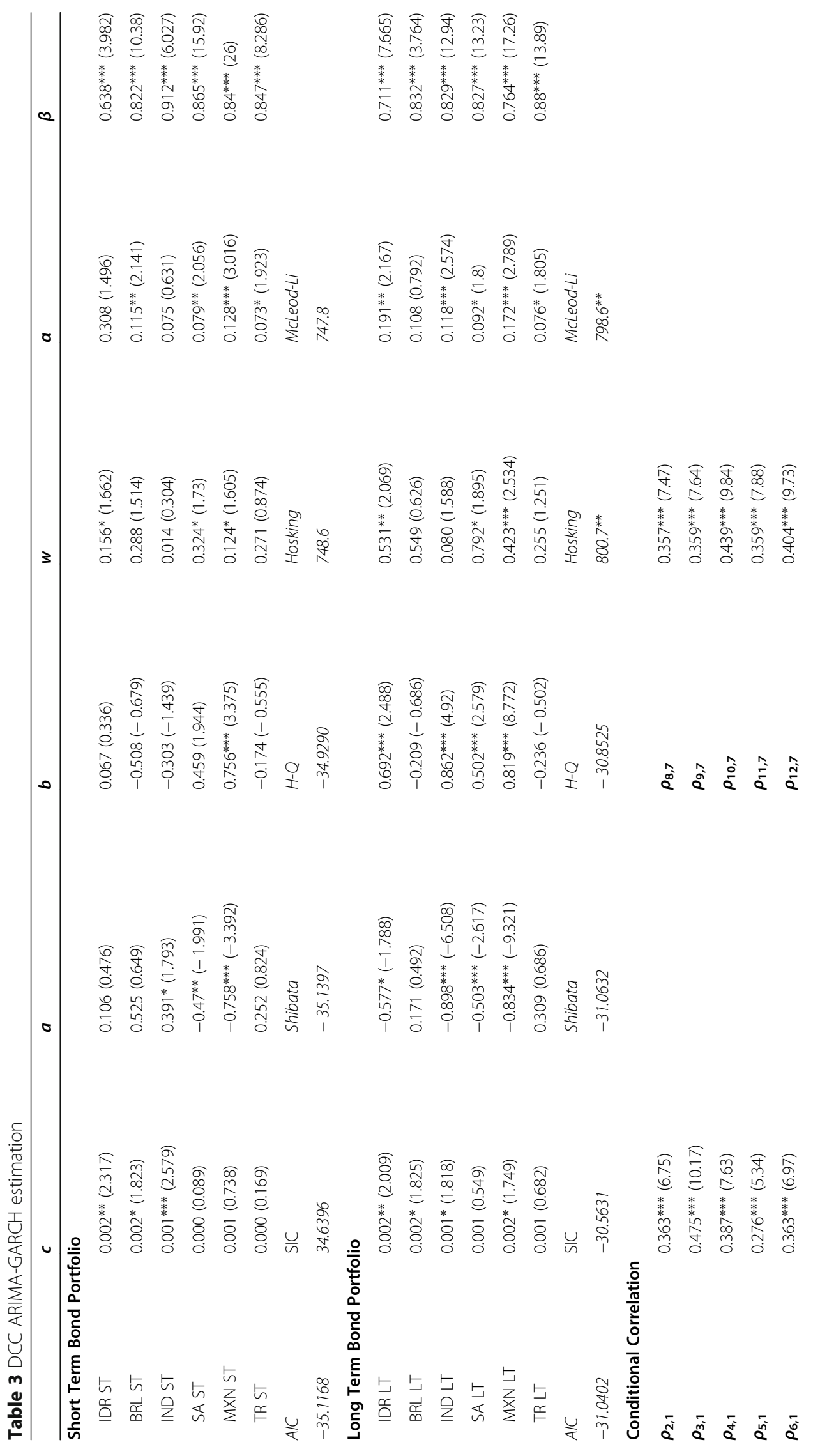




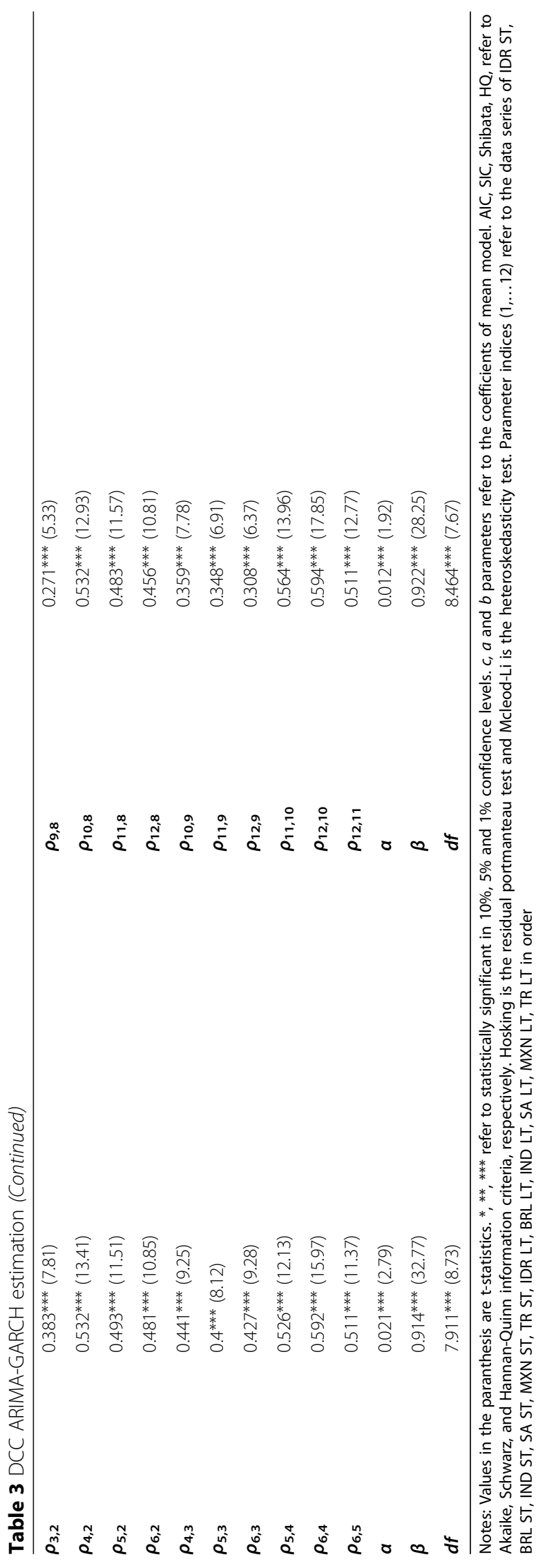


30.000. Although the number of parameters is the same for both portfolios, the IC for the short-term bond portfolio are lower, implying a higher level of goodness of fit.

Meanwhile, the multivariate residual tests of the long-term bond portfolio deliver higher values. ${ }^{3}$ These results imply that the model has limitations in solving the residual autocorrelation and heteroscedasticity.

The empirical results of the next application are shown in Table 4. Here, without modeling the return series, FIGARCH is directly applied to all bonds but in the DCC framework again. For 10 out of the 12 data series, the long memory coefficient $d$ is statistically significant.

For the fractional based models, the level of the $d$ parameter is also critical. If the $d$ coefficient is close to 1 , then the shocks will diminish very slowly, and the model will look like an IGARCH model. However, if the level of this parameter is close to 0 , it will be difficult to see the memory impact, and the model will approach to the plain GARC $\mathrm{H}$ model. Nevertheless, in Table 4, statistically significant long-memory parameters lie in the 0.31-0.66 interval. The $d$ parameters, which are close to 0.5 , also justifies the application of long memory models to this kind of data structure.

Meanwhile, we observe fewer statistically significant $\beta$ parameters in Table 4, compared with that of the previous application: DCC-ARIMA GARCH. For example, for the long-term bonds, only Indonesia and Turkey have these statistically significant parameters. In the previous model, all the $\beta$ coefficients were statistically significant. Two factors are effective in this situation. First, in the previous estimation, we applied the volatility model to the residuals of a mean model that provided healthier volatility estimations. Nevertheless, here in the DCC-FIGARCH estimation the model is directly applied to the data, and the expected return is assumed constant. The second factor relates to the role of $d$. In straightforward GARCH models, the level of $\alpha$ reflects the impact of the recent innovation, as $\beta$ carries the memory that shows the impact of past volatility. However, in FIGA $\mathrm{RCH}$, the impact of previous shocks is exhibited by an adjustable hyperbolic rate $d$. As memory is partially held by $d$, we come up with a lower number of significant $\beta$ parameters.

When we examine the values of $d$ in Table 4 and in the following models (see Tables 5 and 6), we find that Indonesian bonds have the highest numbers, which means that the highest level of persistence is observed in the Indonesian bonds (this situation is also observed in the Hurst exponents, see Preliminary Analysis). Mexico and India are the other two countries with high persistence figures.

Particularly during the post-GFC period, foreign capital flows have been one of the major determinants of EM assets. At the initial stage, unprecedented liquidity actions from the central banks of DMs, particularly the Fed, and low GDP growth rates in the mature economies induced historical amounts of capital flows to EM. However, this situation made the countries that have high external deficits vulnerable to liquidity conditions.

From this viewpoint, the current account balances of Indonesia and Mexico have been much more stable compared with the other countries. For the observation period, the average current account deficit (CAD) to GDP figures of Indonesia and Mexico were $1.1 \%$ and $1.7 \%$, respectively. The deterioration in India had been

${ }^{3}$ See Hosking (1980) and McLeod and Li (1983). 
Table 4 DCC FIGARCH estimation

\begin{tabular}{|c|c|c|c|c|c|}
\hline & $c$ & $w$ & $d$ & $a$ & $\beta$ \\
\hline \multicolumn{6}{|c|}{ Short Term Bond Portfolio } \\
\hline IDR ST & $0.001^{* * *}(2.704)$ & $14.206(0.832)$ & $0.655^{* * *}(4.852)$ & $-0.37(-1.365)$ & $0.079(0.391)$ \\
\hline BRL ST & $0.002^{* *}(2.153)$ & $6.347(1.537)$ & $0.419^{* *}(2.259)$ & $0.226(1.556)$ & $0.507^{* * *}(3.071)$ \\
\hline IND ST & $0.001^{* * *}(3.294)$ & $2.774(0.919)$ & $0.571^{* *}(2.504)$ & $0.181(0.403)$ & $0.614(1.456)$ \\
\hline SA ST & $0(0.066)$ & $7.31(1.569)$ & $0.331^{* *}(2.115)$ & $-0.032(-0.038)$ & $0.227(0.269)$ \\
\hline MXN ST & $0(0.475)$ & $6.602(1.157)$ & $0.601^{* * *}(2.745)$ & $0.123(1.156)$ & $0.649^{* * *}(3.439)$ \\
\hline TR ST & $0(0.11)$ & $5.513(0.837)$ & $0.48(1.026)$ & $0.383^{*}(1.597)$ & $0.714^{* * *}(3.126)$ \\
\hline$A / C$ & $\mathrm{SIC}$ & Shibata & $H-Q$ & Hosking & McLeod-Li \\
\hline-35.0974 & -34.6733 & -35.1158 & -34.9305 & $792.6^{* *}$ & $791.8^{* *}$ \\
\hline \multicolumn{6}{|c|}{ Long Term Bond Portfolio } \\
\hline IDR LT & $0.002^{* *}(2.218)$ & $28.827(0.843)$ & $0.587^{* * *}(4.204)$ & $-0.425^{*}(-1.658)$ & $0.05(0.227)$ \\
\hline BRL LT & $0.002^{*}(1.887)$ & $8.421^{* * *}(2.979)$ & $0.32^{* * *}(2.846)$ & $0.112(0.558)$ & $0.346(1.521)$ \\
\hline IND LT & $0.001^{* *}(2.18)$ & $3.271(1.509)$ & $0.389^{* * *}(4.217)$ & $-0.756^{* * *}(-6.497)$ & $-0.608^{*}(-1.745)$ \\
\hline SA LT & $0.001(0.909)$ & $11.914(1.378)$ & $0.263(1.212)$ & $-0.457(-1.28)$ & $-0.28(-0.81)$ \\
\hline MXN LT & $0.002(1.408)$ & $8.969(1.536)$ & $0.403^{* *}(2.361)$ & $-0.352(-0.415)$ & $-0.051(-0.053)$ \\
\hline TR LT & $0.001(0.713)$ & $5.693^{* * *}(3.495)$ & $0.315^{* *}(2.345)$ & $0.303^{*}(1.801)$ & $0.532^{* * *}(2.7)$ \\
\hline AIC & $\mathrm{SIC}$ & Shibata & $H-Q$ & Hosking & McLeod-Li \\
\hline-31.0374 & -30.6133 & -31.0558 & -30.8705 & 760.1 & 759.8 \\
\hline \multicolumn{6}{|c|}{ Conditional Correlation } \\
\hline$\rho_{2,1}$ & $0.374^{* * *}(0.05)$ & & $\rho_{8,7}$ & $0.348^{* * *}(7.29)$ & \\
\hline$\rho_{3,1}$ & $0.479^{* * *}(0.04)$ & & $\rho_{9,7}$ & $0.371^{* * *}(7.98)$ & \\
\hline$\rho_{4,1}$ & $0.391^{* * *}(0.05)$ & & $\rho_{10,7}$ & $0.445^{* * *}(10.32)$ & \\
\hline$\rho_{5,1}$ & $0.286^{* * *}(0.05)$ & & $\rho_{11,7}$ & $0.362^{* * *}(7.56)$ & \\
\hline$\rho_{6,1}$ & $0.379 * * *(0.05)$ & & $\rho_{12,7}$ & $0.418^{* * *}(10.21)$ & \\
\hline$\rho_{3,2}$ & $0.39^{* * *}(0.05)$ & & $\rho_{9,8}$ & $0.278^{* * *}(5.42)$ & \\
\hline$\rho_{4,2}$ & $0.542^{* * *}(0.04)$ & & $\rho_{10,8}$ & $0.529^{* * *}(13.02)$ & \\
\hline$\rho_{5,2}$ & $0.501^{* * *}(0.04)$ & & $\rho_{11,8}$ & $0.471^{* * *}(11.16)$ & \\
\hline$\rho_{6,2}$ & $0.489^{* * *}(0.04)$ & & $\rho_{12,8}$ & $0.447^{* * *}(10.73)$ & \\
\hline$\rho_{4,3}$ & $0.436^{* * *}(0.05)$ & & $\rho_{10,9}$ & $0.374^{* * *}(7.96)$ & \\
\hline$\rho_{5,3}$ & $0.407^{* * *}(0.05)$ & & $\rho_{11,9}$ & $0.352^{* * *}(6.98)$ & \\
\hline$\rho_{6,3}$ & $0.443^{* * *}(0.05)$ & & $\rho_{12,9}$ & $0.327^{* * *}(6.78)$ & \\
\hline$\rho_{5,4}$ & $0.52^{* * *}(0.04)$ & & $\rho_{11,10}$ & $0.553^{* * *}(13.49)$ & \\
\hline$\rho_{6,4}$ & $0.589 * * *(0.04)$ & & $\rho_{12,10}$ & $0.583^{* * *}(17.15)$ & \\
\hline$\rho_{6,5}$ & $0.506^{* * *}(0.05)$ & & $\rho_{12,11}$ & $0.5^{* * *}(12.57)$ & \\
\hline$a$ & $0.021^{* * *}(0.01)$ & & $a$ & $0.015^{* *}(1.99)$ & \\
\hline$\beta$ & $0.912^{* * *}(0.03)$ & & $\beta$ & $0.905^{* * *}(21.42)$ & \\
\hline$d f$ & $7.999 * * *(0.98)$ & & $d f$ & $8.683^{* * *}(7.35)$ & \\
\hline
\end{tabular}

Notes: Values in the paranthesis are t-statistics. ${ }^{*}, * * * *$ refer to statistically significant in $10 \%, 5 \%$ and $1 \%$ confidence levels. C, a and b parameters refer to the coefficients of mean model. AIC, SIC, Shibata, H-Q, refer to Akaike, Schwarz, and Hannan-Quinn information criteria, respectively. Hosking is the residual portmanteau test and Mcleod-Li is the heteroskedasticity test. Parameter indices $(1, \ldots 12)$ refer to the data series of IDR ST, BRL ST, IND ST, SA ST, MXN ST, TR ST, IDR LT, BRL LT, IND LT, SA LT, MXN LT, TR LT in order 


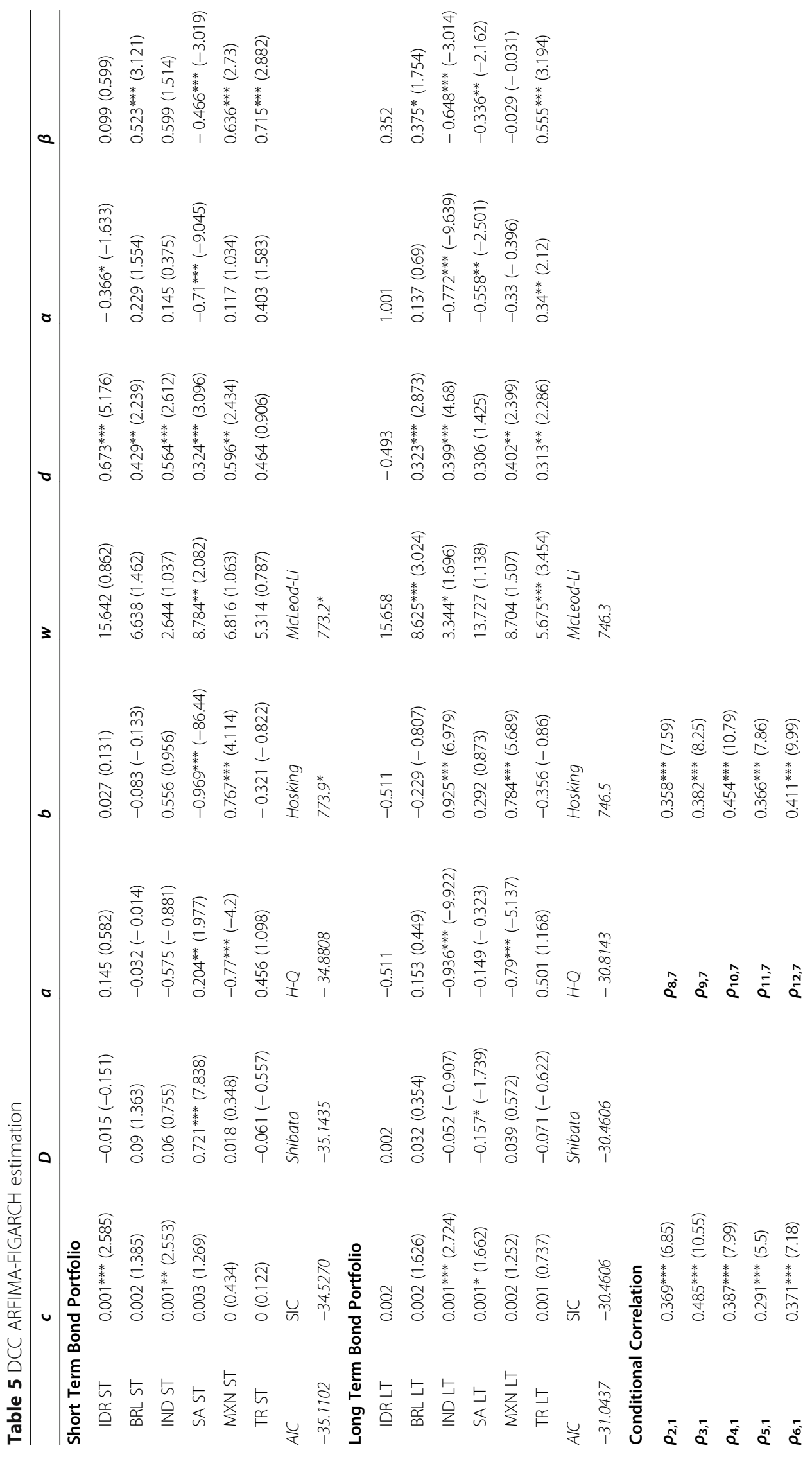




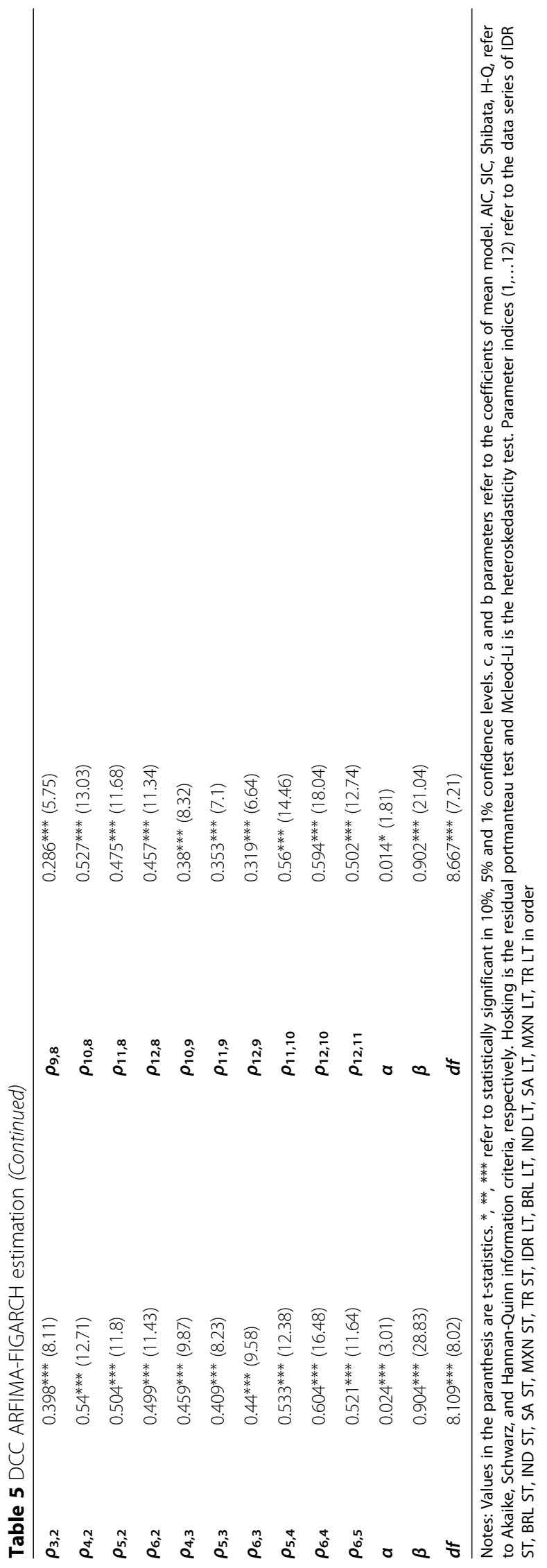




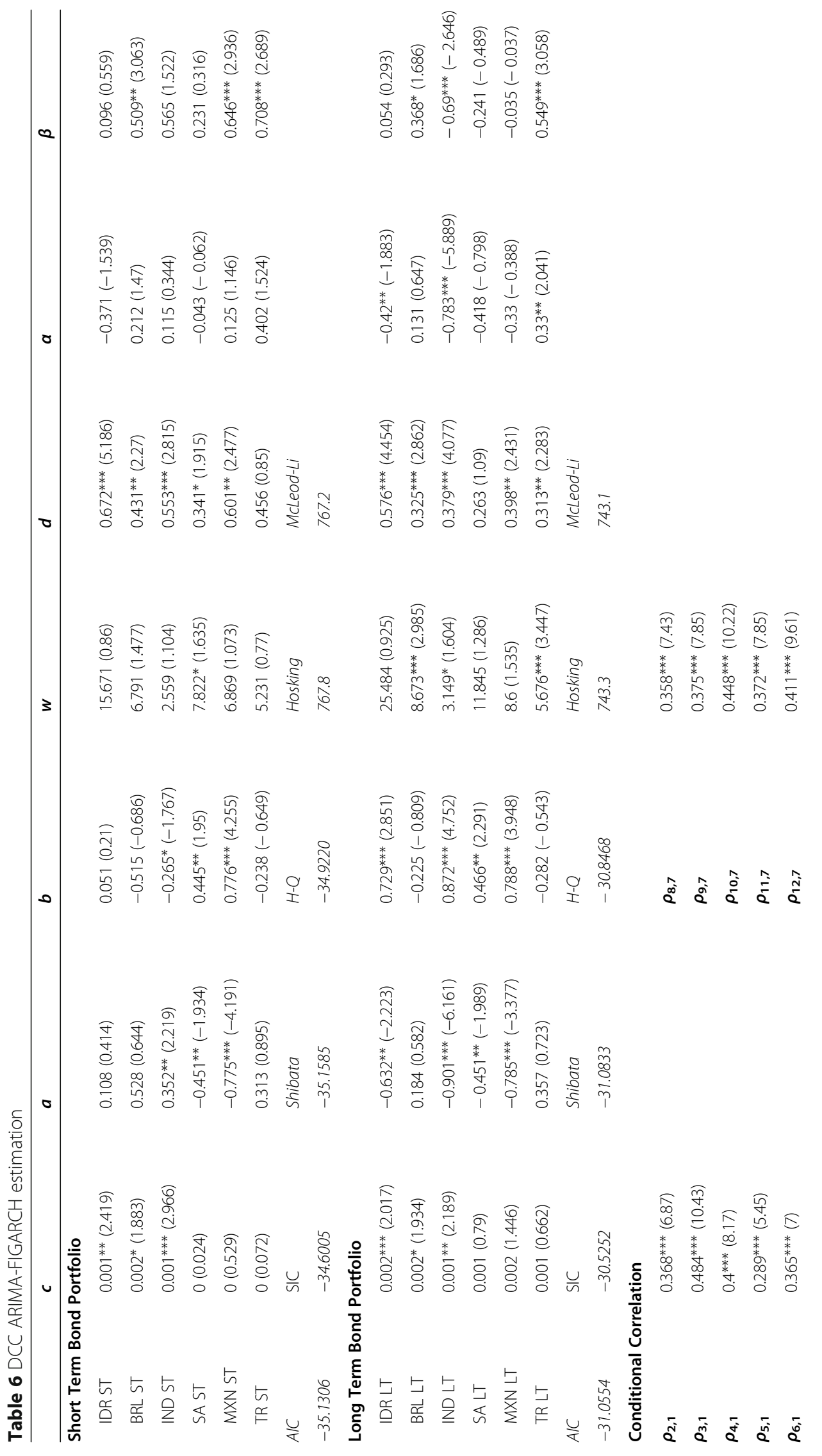




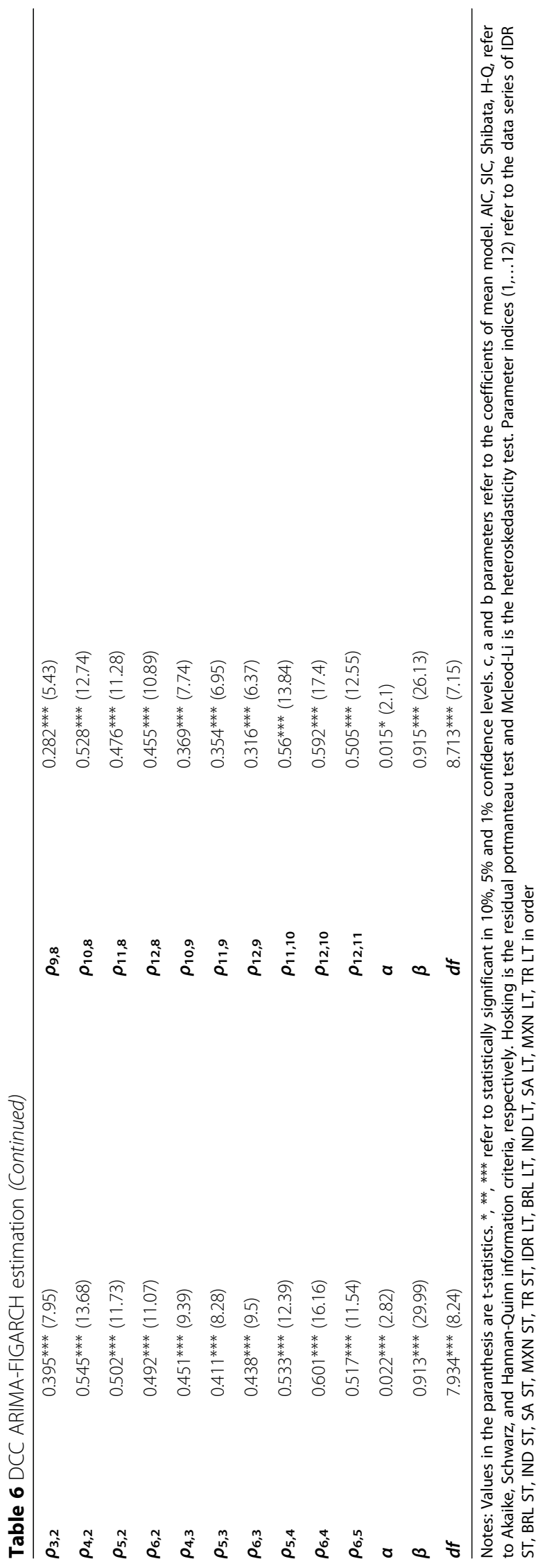


limited, and its recovery was fast. However, Brazil, South Africa, and Turkey have been evaluated as the weakest members of the major EMs, with sharply widening external deficits.

The events that changed the conditions of easy liquidity, such as the taper tantrum or the lift-off decision, ${ }^{4}$ significantly affected the fund flows to these countries since their economies had become much more dependent on external capital. Particularly, the South African and Turkish economies sharply oscillated during this period. The CAD figures of South Africa had tested 6\% of GDP, and as of 2011 year end, Turkish figures had reached all-time-high levels of $9 \%$. Moreover, apart from these countries' political developments (like election cycles) were other events that affected the volatility structure.

To summarize, vulnerabilities to global liquidity conditions had partially diminished the impact of long memory in the volatilities, as the liquidity conditions sharply changed during this period. As a result of the economic situation, even the $d$ parameters of Turkey's short-term bonds and South Africa's long-term bonds failed to be statistically significant in the fractional models below.

In terms of goodness of fit, the Schwarz and Hannan-Quinn IC are lower than those in the previous model. Because the number of observations is large enough, the better results of these Bayesian approaches are noteworthy. However, as in the previous case, residual portmanteau test results are high for the short-term bond portfolio; thus, further modeling is needed to lower the autocorrelation and heteroscedasticity values.

In the third example, fractional models are applied to both the mean and the volatility. A single-step ARFIMA is applied on the mean, as FIGARCH is used for the volatility modeling. The parameter estimations and t-statistics are listed in Table 5 . In the mean equation, the long memory parameters are statistically significant for the shortterm and long-term bonds of South Africa. The auto-regression and moving average parameters of the mean models are statistically significant only for one-third of the data series. The short-term bonds of South Africa and Mexico and the long-term bonds of India and Mexico are some of the examples.

In the volatility modeling, similar to the previous application, most of the $d$ coefficients are statistically significant. In Table 5 , only the volatilities of Turkish bonds and the long-term bonds of South Africa do not exhibit long memory impact. Meanwhile, the modeling could not be performed for the Indonesian long-term bonds because the $d$ coefficient is negative, and all of the mean and volatility parameters are statistically insignificant.

The DCC-ARFIMA FIGARCH model has a lower Shibata IC for the short-term bond portfolio, and the Akaike IC for both short-term and long-term portfolios. The residual diagnostics here are also better, as compared with the previous applications.

Considering the test results of the fractional parameters in Table 5, the long-memory impact in the mean model is questionable. Thus, plain and fractional models are combined in the last application below. The empirical results of the fourth application are listed in Table 6. In this last step, the mean model is estimated under the plain ARIMA approach, and the fractional modeling is performed only for the volatility.

In Table 6, most of the mean model parameters (especially for the long-term bond portfolio) show statistically significant auto-regressive and moving average coefficients. 
Meanwhile, the volatilities show a long memory feature, as the $d$ coefficients are statistically significant for 10 out of the 12 samples. These parameters are estimated at around 0.5 levels; the definite necessity of the fractional modeling is observed again. Furthermore, six out of the 12 data series still have statistically significant $\beta$ coefficients, together with long-range dependence.

The model's diagnostic check also shows sufficient IC and residual diagnostics. The residual diagnostics imply that fractional volatility modeling is better in terms of overcoming heteroskedasticity. For each case, the fractional based models deliver better results compared with the benchmark model. However, DCC ARIMA-FIGARCH has the lowest values of the Akaike and Shibata IC for both portfolios. Among the eight goodness of fit tests for each model the DCC ARIMA-FIGARCH model delivers the lowest level of IC for four times. Applying the parameter tests and IC contribute to the robustness of the model. Specifically, the levels of the statistically significant fractional parameter $d$ under various conditions (for two different distribution assumptions and various samples) are also supportive of the model selection. Moreover, the residual tests show that the autocorrelation and the heteroscedasticity are untangled for both portfolios.

In the framework of this study, the correlations are evaluated as being dynamic, and the estimations of each model are listed in each of the tables. Apart from standard correlations, DCC estimation is composed of three parts, and two of them are time-varying. All coefficients add up to 1 (i.e., constitute the estimated correlation matrix), and in the table, the time-varying $\alpha$ and $\beta$ coefficients are listed. $\beta$ shows the level of dependence of the correlation matrix to the most recent estimated matrix, while $\alpha$ determines the contribution of the most recent residuals of the GARCH model. In other words, $\alpha$ adjusts the estimation with the most recent innovations. In the DCC, the remaining part, the covariance matrix of the error terms (which is the average product of the standardized residuals of the model) is constant.

The outputs of the short- and long-term bonds are listed separately in Tables 3, 4, 5 and 6 . In the tables, the left- (right-) hand side of each headline refers to the short(long-) term bond portfolio. The $\beta$ and pairwise coefficients are statistically significant for all data series. For the short-term bond series, the $\alpha$ parameters are also significant at the $1 \%$ level. However, the $\alpha$ parameters in the DCC estimations of the ARIMAGARCH and ARFIMA-FIGARCH models are not statistically significant under the 5\% threshold.

The parameter estimations of the DCC models are close to each other (see Tables 3, 4,5 and 6). As the $\beta$ levels are above $90 \%$, and the $\alpha$ levels are around $2 \%$ for all models, we can infer that the correlations are persistent; the change caused by the recent innovations is slow. The values and related tests exhibit signs of long memory in the correlation part as well.

In the $\rho$ parameters, the highest figures are observed in the cross-correlation estimations of South Africa's and Turkey's bonds. Since these parameters are constant, this adds additional persistence impact on the estimations. In line with our economic interpretation about the volatility estimations above, this situation seems plausible. During the observation period, the macroeconomic dynamics of 
Turkey and South Africa were similar, making their bond markets behave similarly.

Meanwhile, from the perspective of forecasting, the parameters for each model are very similar. This implies that the level of individual volatilities, not the conditional correlations, is the determinant of the difference in the conditional covariance matrices. In other words, the risk estimation is mostly based on the forecasting of the individual volatilities.

\section{Out-of-sample value at risk analysis}

Out-of-sample performances are examined for a period of 1 year, based on a rolling window analysis. Conditional mean, conditional volatility, and dynamic correlation forecasts of a model based on rolling samples are generated for 52 weeks, covering the period September 1, 2017 to August 31, 2018. From these forecasts, the expected returns of the portfolios are calculated; correlation matrices and individual volatilities are used to construct manually the portfolio variances.

For each week, 54 parameters (12 individual returns, 12 volatilities, and 30 pairwise correlations) are forecasted and taken for further calculation. This burdensome process is repeated for each of the 52 weeks. As further computations are required for the portfolio weighting strategies at each step, the process becomes even more complicated.

As a broader analysis, the process can be performed under different distribution conditions such as the normal and $t$-distributions for all of the models. However, in this section, due to the intensive process involved, one model is examined under a selected distribution condition, and the rest is left for future studies. The model and distribution selections are based on the in-sample test results. In line with the outcomes of the previous section for the models and particularly the IC results under the normal and $t$-distributions, DCC ARIMA-FIGARCH is chosen for further analysis. The statistical analysis of the individual assets and the model outcomes that are examined for both distributions particularly pointed to the selection of a $t$-distribution.

The VaR analysis of these forecasts is performed with respect to five different weighting methods, as shown in Table 7. The weighting strategies consider both static and dynamic approaches. As examples of static approaches, equally weighted, GDP-weighted, and market cap- (MCAP) weighted strategies are adopted. These strategies can reflect (or develop) the structures of the related passive investments.

For the dynamic portfolios, biweekly-changing efficient portfolios are considered. The mean-variance method of the modern portfolio theory is a common approach that covers the dynamic hedging ratios among different asset classes (see Markowitz 1952). Each week, model forecasts of the mean, volatility, and dynamic correlation variables are evaluated for portfolio optimization. The optimizations are performed with the objective of mean-variance (MV) efficiency, thereby maximizing the portfolio return per additional risk. The portfolios comprise only long positions; the possibility of short sales and leverage are restricted. There are no individual constraints on assets. In this way, for every period, asset weights for the short- and long-term bond portfolios are calculated. In Table 7, the average values from the weights of 52 different portfolios for short- and long-term bonds (total of 104) are listed. 
Table 7 Sample portfolios

\begin{tabular}{|c|c|c|c|}
\hline \multicolumn{4}{|c|}{ Asset Weights } \\
\hline Bonds & $\begin{array}{l}\text { Homogen (Short-Term, } \\
\text { Long-Term) }\end{array}$ & $\begin{array}{l}\text { GDP Weighted (Short- } \\
\text { Term, Long-Term) }\end{array}$ & $\begin{array}{l}\text { MCAP Weighted (Short- } \\
\text { Term, Long-Term) }\end{array}$ \\
\hline Indonesia & $17 \%$ & $13 \%$ & $5 \%$ \\
\hline Brazil & $17 \%$ & $26 \%$ & $52 \%$ \\
\hline India & $17 \%$ & $33 \%$ & $21 \%$ \\
\hline South Africa & $17 \%$ & $4 \%$ & $6 \%$ \\
\hline Mexico & $17 \%$ & $14 \%$ & $12 \%$ \\
\hline \multirow[t]{2}{*}{ Turkey } & $17 \%$ & $11 \%$ & $4 \%$ \\
\hline & $\begin{array}{l}\text { MV-Optimal Portfolios } \\
\text { Average (Short-Term) }\end{array}$ & \multicolumn{2}{|l|}{$\begin{array}{l}\text { MV-Optimal Portfolios } \\
\text { Average (Long-Term) }\end{array}$} \\
\hline Indonesia & $29 \%$ & \multicolumn{2}{|l|}{$22 \%$} \\
\hline Brazil & $19 \%$ & \multicolumn{2}{|l|}{$17 \%$} \\
\hline India & $41 \%$ & \multicolumn{2}{|l|}{$34 \%$} \\
\hline South Africa & $5 \%$ & \multicolumn{2}{|l|}{$10 \%$} \\
\hline Mexico & $3 \%$ & \multicolumn{2}{|l|}{$15 \%$} \\
\hline Turkey & $3 \%$ & \multicolumn{2}{|l|}{$2 \%$} \\
\hline
\end{tabular}

In Table 8, for all portfolios, there is supposed to be five and two failures out of 52 observations in the $90 \% \mathrm{VaR}$ and $95 \% \mathrm{VaR}$, respectively.

For the short-term bond portfolios, the model estimated six failures in the $90 \% \mathrm{VaR}$ and four failures in the 95\% VaR (three for the MCAP weighted portfolio). The numbers are close to actual failures, and some of the exceedances occurred with tiny breaches, for example, 2 bps. Moreover, we can conclude that the estimations are relatively cautious.

For the long-term bond portfolios, the model's results are better: the $95 \% \mathrm{VaR}$ is crossed two times, as it is supposed to be in the GDP-weighted, MCAP-weighted, and

Table 8 VaR statistics

\begin{tabular}{|c|c|c|c|c|c|c|}
\hline & \multicolumn{2}{|c|}{ Failure } & \multicolumn{2}{|l|}{ Kupiec Test } & \multicolumn{2}{|c|}{ Christoffersen Test } \\
\hline & $90 \%$ & $95 \%$ & $90 \%$ & $95 \%$ & $90 \%$ & $95 \%$ \\
\hline \multicolumn{7}{|l|}{ ST Bond Portfolios } \\
\hline Homogen Portfolio & $6 / 5$ & $4 / 2$ & $0.131(0.717)$ & $0.686(0.407)$ & $1.736(0.42)$ & $1.368(0.505)$ \\
\hline GDP Weighted Portfolio & $6 / 5$ & $4 / 2$ & $0.131(0.717)$ & $0.686(0.407)$ & $1.736(0.42)$ & $1.368(0.505)$ \\
\hline MCAP Weighted Portfolio & $6 / 5$ & $3 / 2$ & $0.131(0.717)$ & $0.062(0.804)$ & $1.736(0.42)$ & $0.437(0.804)$ \\
\hline MV-Optimal Portfolios & $6 / 5$ & $4 / 2$ & $0.131(0.717)$ & $0.686(0.407)$ & $1.453(0.48)$ & $1.368(0.505)$ \\
\hline \multicolumn{7}{|l|}{ LT Bond Portfolios } \\
\hline Homogen Portfolio & $6 / 5$ & $4 / 2$ & $0.131(0.717)$ & $0.686(0.407)$ & $1.736(0.42)$ & $1.368(0.505)$ \\
\hline GDP Weighted Portfolio & $7 / 5$ & $2 / 2$ & $0.632(0.427)$ & $2.868(0.238)$ & $0.158(0.691)$ & $0.321(0.852)$ \\
\hline MCAP Weighted Portfolio & $6 / 5$ & $2 / 2$ & $0.131(0.717)$ & $0.158(0.691)$ & $1.736(0.42)$ & $0.321(0.852)$ \\
\hline MV-Optimal Portfolios & $6 / 5$ & $2 / 2$ & $0.131(0.717)$ & $0.158(0.691)$ & $1.736(0.42)$ & $0.321(0.852)$ \\
\hline
\end{tabular}

Numbers in the parantheses are $p$ - values. All results are statistically significant; star signs are not added 
MV-efficient long-term bond portfolios. For the GDP-weighted long-term portfolio, there are two more failures than the assumption of $90 \% \mathrm{VaR}$ (although, one of the failures occurred with only $0.4 \mathrm{bps}$, which is a negligible level of exceedance). For the homogenous, MCAP-weighted, and MV-efficient portfolios, only one more breach happened.

In line with these outcomes, the Kupiec and Christoffersen test results are shown in Table 8. The unconditional coverage test of Kupiec deals with the accuracy of breaches. In the Kupiec test, the log-likelihood function, $L R_{P o F}=-2 \log \left(\frac{(1-\alpha)^{N-s} \alpha^{s}}{\left(1-\frac{s}{N}\right)^{N-s}\left(\frac{s}{N}\right)^{s}}\right.$, is asymptotically chi-squared, where $s$ is the number of failures and $N$ is the number of observations. The $(1-\alpha)$ VaR method fails if the function exceeds the critical value (see Kupiec 1995). The conditional coverage test of Christoffersen (1998) elaborates on the independence of failures. The log-likelihood function, $L R_{C C I}=-2 \log \left\{\left(\frac{p}{p_{0}}\right)^{s_{00}}\left(\frac{1-p}{1-p_{0}}\right)^{s_{01}}\right.$ $\left.\left(\frac{p}{p_{1}}\right)^{s_{10}}\left(\frac{1-p}{1-p_{1}}\right)^{s_{11}}\right\}$, similarly follows a chi-squared distribution with special counting parameters. $s_{00}$ refers to the number of two consecutive periods without failure, and $s_{11}$ refers to the number of two consecutive periods with failure. $s_{01}$ and $s_{10}$ represents the number of the periods without failure followed by a period of failure, and the other way round, respectively. $p_{0}, p_{1}, p$ are the probabilities or the share of the counts; $p_{0}=\frac{s_{01}}{s_{00}+s_{01}} ; p_{1}=\frac{s_{11}}{s_{10}+s_{11}} ;$ and $p=\left(s_{01}+s_{11}\right) /\left(s_{00}+s_{01}+s_{10}+s_{11}\right)$.

The test results are presented in Table 8 . The number of failures and their independence are in-line with the VaR assumptions. The model performance for each one of the static and dynamic portfolios is sufficient. With high $p$-values, these results imply that the DCC ARIMA-FIGARCH is a good application from the VaR perspective.

As an additional assessment, the results are also compared with the estimations of the plain approaches: delta-normal and historical simulation. Although it is not presented here, especially for the long-term bond portfolios, the time series model delivers performance that is significantly better than both of these basic approaches.

\section{Conclusion}

Bonds and bills have been one of the major asset classes in almost all portfolios. In the post-millennium era with the yield-hunting motivation becoming prevalent, EM bonds have received the attention of global investors. These days, all of the major asset management houses provide EM bond funds for their investors. However, there is a lack of literature about the management of EM bond portfolios, especially from the risk perspective.

This study covers all the local bonds of six major EM economies that have been actively traded in the last 10 years. We filter 203 different bonds and constructed hypothetical portfolios to study the performance of certain risk management tools.

Volatility modeling is a critical part of this study, and relatively new approaches are applied, together with common methods. Fractionally integrated models are evaluated in this manner. In the academic literature, these models have been used in a univariate framework and applied to specific asset classes such as the commodity and stock markets. For the other asset classes, especially those concerning the fixed income market, there is a limited number of univariate applications. In the academic literature, this study is the first to tackle the multivariate analysis of EM bonds and apply the fractional modeling concept. 
We deploy four models in the DCC framework: ARIMA-GARCH, FIGARCH, ARFI MA-FIGARCH, and ARIMA-FIGARCH. The parameter estimations and in-sample performances of these four models are examined. All analyses are made under the normal and $t$-distributions.

First, for the mean models, more than half of the data series show auto-regressive features. The AR coefficients of both the short- and long-term bonds of India, South Africa, and Mexico and the long-term bonds of Indonesia are statistically significant. Moreover, except for Brazil, the returns of all long-term bonds have moving average impacts at statistically significant levels.

Meanwhile, regarding the return series, it is difficult to determine the impact of long memory. Unlike in the case of the plain ARIMA model, for most of the other cases, the parameters of the ARFIMA model have no statistical significant.

Regarding volatility, the GARCH model have statistically significant $\beta$ coefficients, which indicates the impact of memory. Furthermore, except for three data series, the $\alpha$ parameters are also significant. The fractionally integrated volatility models are applied to the residuals of the approaches: unconditional mean, ARIMA, and an ARFIMA model. In the applications, evidence of long memory is detected, at least once for almost all the assets. Most of the time $d$ coefficients are statistically significant. Furthermore, for each case, the level of $d$ lies at around 0.5; this indicates the need for fractionally integrated modeling.

Third, for the DCC part of each mean and volatility modeling, almost all model parameters of conditional correlations are statistically significant. For almost all models, the individual coefficients, as well as the $\alpha$ and $\beta$ parameters of the DCC models, are positive at the $1 \%$ significance levels, which signifies dependence on the previous innovations.

From the diagnostic checking results, the IC and residual test outputs of the fractionally integrated models are better than those of the benchmark ARIMA-GARCH model. In conclusion, the DCC ARIMA-FIGARCH model have better goodness of fit results for both the short- and long-term bonds, in line with the results of the tests of parameter estimations.

For the out-of-sample performance evaluation, the VaR analysis is conducted based on one-year rolling window forecasts. The portfolios are populated in static and dynamic forms. Homogeneously weighted, GDP weighted, and market-capweighted portfolios are considered as static proxies. Furthermore, mean-variance efficient portfolios (optimal weighting strategy) for each week are also taken into consideration.

The Kupiec and Christoffersen tests indicate that DCC ARIMA-FIGARCH is a sufficient VaR model for various static and dynamic EM portfolios. The VaR analysis is performed only for the DCC ARIMA-FIGARCH model due to the intensiveness of the process.

This study provides implications for both investors and policymakers. The analysis results suggest that the risk management of EM bond investments should consider the long memory concept, as the empirical findings are from direct applications. Not only index-tracking static portfolios but also dynamically managed active portfolios should consider the fractional methods when conducting risk analysis. 
Second, in the academic literature, persistence of shocks is usually observed in high-risk assets such as commodities or equities. Meanwhile, government bonds, especially the short-term ones, are usually perceived as low-risk assets, and their yields are considered as the benchmarks of local interest rates. In most countries, the volatility of bonds and their yields affecthe policies of the governments and the central banks. As a liquidity tool, it is common for central banks to intervene actively in the bond markets. Although the situation is not the same for emerging countries and their assets, the evidence of volatility persistence in government bonds is noteworthy from this viewpoint. Once a shock in government bonds takes place, it takes a long time for its effects to diminish, and this may require specific approaches. The application of fractional models can be useful for this core asset class, which has a significant role in liquidity policies.

For future work, the application of the other fractional models, which cover an asymmetric power or leverage effects, can be evaluated. In addition, risk analysis can be conducted using different approaches such as risk metrics and variance-covariance. Regarding correlation, this study only dealt with dynamic correlation. An analysis of constant correlation models and other multivariate models can also be performed in the EM bonds universe.

\section{Appendix}

Table 9 ISIN codes of the bonds

Indonesia: IDG000006206, IDG000006701, IDG000010901, IDG000008202, IDG000010604, IDG000005901, IDG000009408, IDG000005802, IDG000005703, IDG000008400, IDG000006404, IDG000005406, IDG000004805, IDG000005406, IDG000005604, IDG000004607, IDG000005208, IDG000004102, IDG000010307, IDG000009804, IDG000009507, IDG000007204, IDG000012006, IDG000010208, IDG000010000, IDG000009101, IDG000006206, IDG000006701, IDG000008202, IDG0000066305

Brazil: BRSTNCLTN7J0, BRSTNCLTN7H4, BRSTNCLTN7G6, BRSTNCLTN764, BRSTNCLTN7E1, BRSTNCLTN7A9, BRSTNCLTN780, BRSTNCLTN707, BRSTNCLTN6X3, BRSTNCLTN749, BRSTNCLTN6W5, BRSTNCLTN715, BRSTNCLTN6S3, BRSTNCLTN6Y1, BRSTNCLTN6N4, BRSTNCLTN6R5, BRSTNCNTF071, BRSTNCNTFOJ3, BRSTNCNTF063, BRSTNCLTN6C7, BRSTNCLTN6B9, BRSTNCLTN699, BRSTNCLTN681, BRSTNCNTF106, BRSTNCNTF1P8, BRSTNCNTF170, BRSTNCNTF0N5, BRSTNCNTF147, BRSTNCNTF0G9, BRSTNCNTFON5, BRSTNCNTFOG9, BRSTNCNTF071, BRSTNCNTFOJ3

India: IN0020180017, IN0020140029, IN0020100015, IN0020120054, IN0020140029, IN0020100015, IN0020020171, IN0020130038, IN0020080068, IN0020130038, IN0020110014, IN0020120021, IN0020020031, IN0020120021, IN0020020031, IN0020120021, IN0020090059, IN0020060219, IN0020090059, IN0020100023, IN0020090018, IN0020100023, IN0020020122, IN0020020056, IN0020010057, IN0020020213, IN0020020155, IN0020030030, IN0020170174, IN0020170026, IN0020160035, IN0020150093, IN0020150036, IN0020140045, IN0020130061, IDG000012006, IN0020130061, IN0020130012, IN0020120013, IN0020110030, IN0020070051, IN0020110030, IN0020110022, IN0020100015, IN0020020171, IN0020020098, IN0020070010, IN0020060219, IN0020080019, IN0020020163, IN0020070010, IN0020060219

South Africa: ZAG000024738, ZAG000021841, ZAG000021833, ZAG000099870, ZAG000021833, ZAG000021841, ZAG000010547, ZAG000024720, ZAG000044132, ZAG000010539, ZAG000016320, ZAG000096165, ZAG000030396, ZAG000024738, ZAG000021841

Mexico: MXOMGO0000L1, MXOMGO0000VO, MXOMGO0000G1, MXOMGO0000F3, MX0MGO0000S6, MXOMGO000005, MXOMGO0000M9, MXOMGO0000K3, MX0MGO0000A4, MXMOGO000011, MXOMGO0000E6, MXOMGO000052, MX0MGO000094, MX0MGO000037, MXM7GO000014, MXOMGO0000D8, MX0MGO0000Y4, MXOMGO000078, MX0MGO000003, MXOMGO0000Q0, MXOMGO0000N7, MXOMGO0000L1, MXOMGO0000G1, MXOMGO0000F3, MXOMGO0000CO

Turkey: TRT080720T19, TRT050220T17, TRT131119T19, TRT150120T16, TRT100719T18, TRT141118T19, TRT110718T18, TRT140218T10, TRT080317T18, TRT140617T17, TRT080317T18, TRT161116T19, TRT130716T18, TRT071015T12, TRT130515T11, TRT070115T13, TRT060814T18, TRT050314T14, TRT041213T23, TRT091013T12, TRT090113T13, TRT071112T14, TRT080812T26, TRT070312T14, TRT030811T14, TRT020211T11, TRT031110T10, TRT140410T16, TRT071009T51, TRT050809T16, TRT080328T15, TRT110827T16, TRT240227T17, TRT110226T13, TRT120325T12, TRT240724T15, TRT200324T13, TRT080323T10, TRT140922T17, TRT120122T17, TRT150120T16, TRT210721T11, TRT060121T16, TRT150120T16, TRT060814T18, TRT070312T14, TRT140410T16, TRT070312T14 


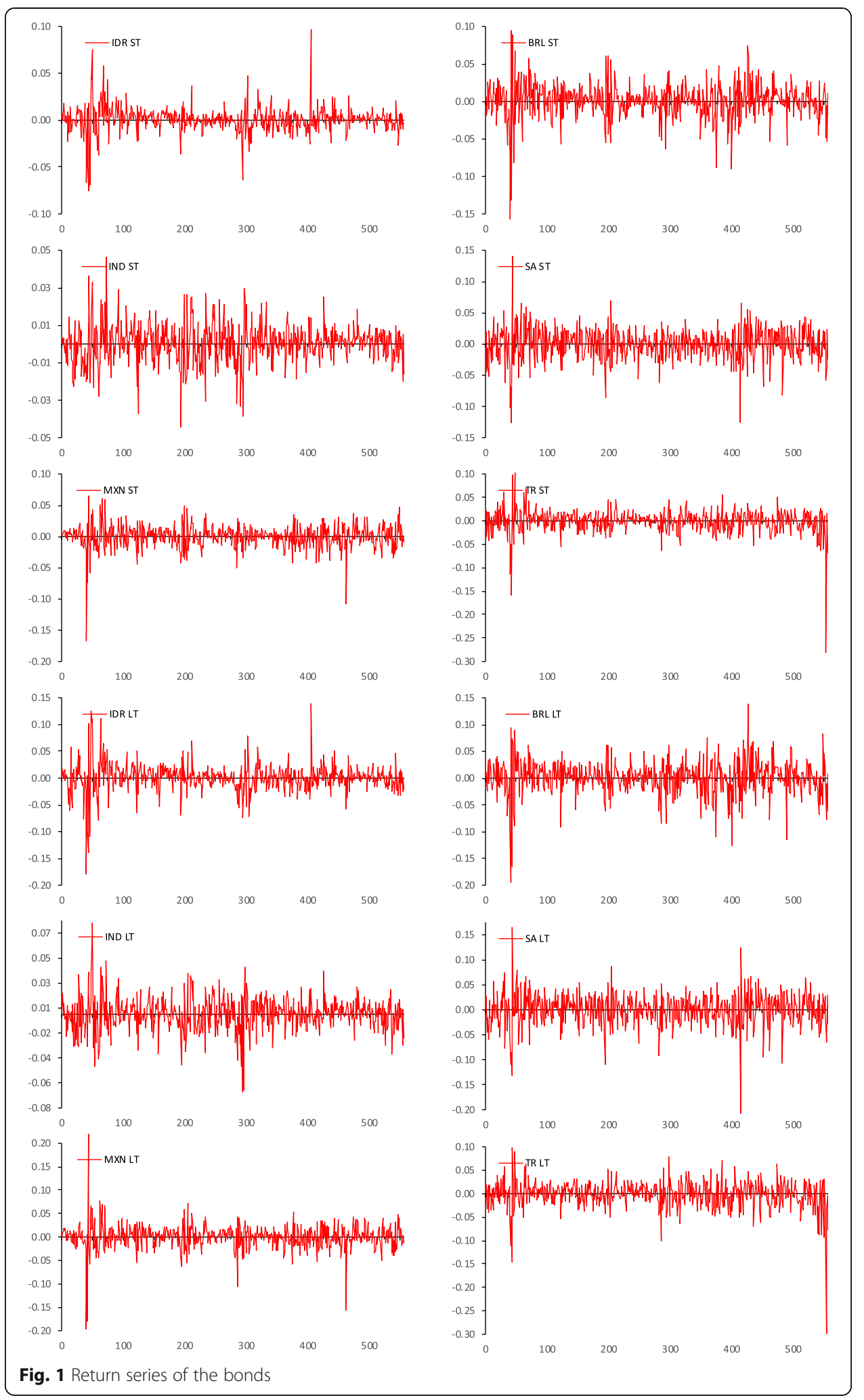




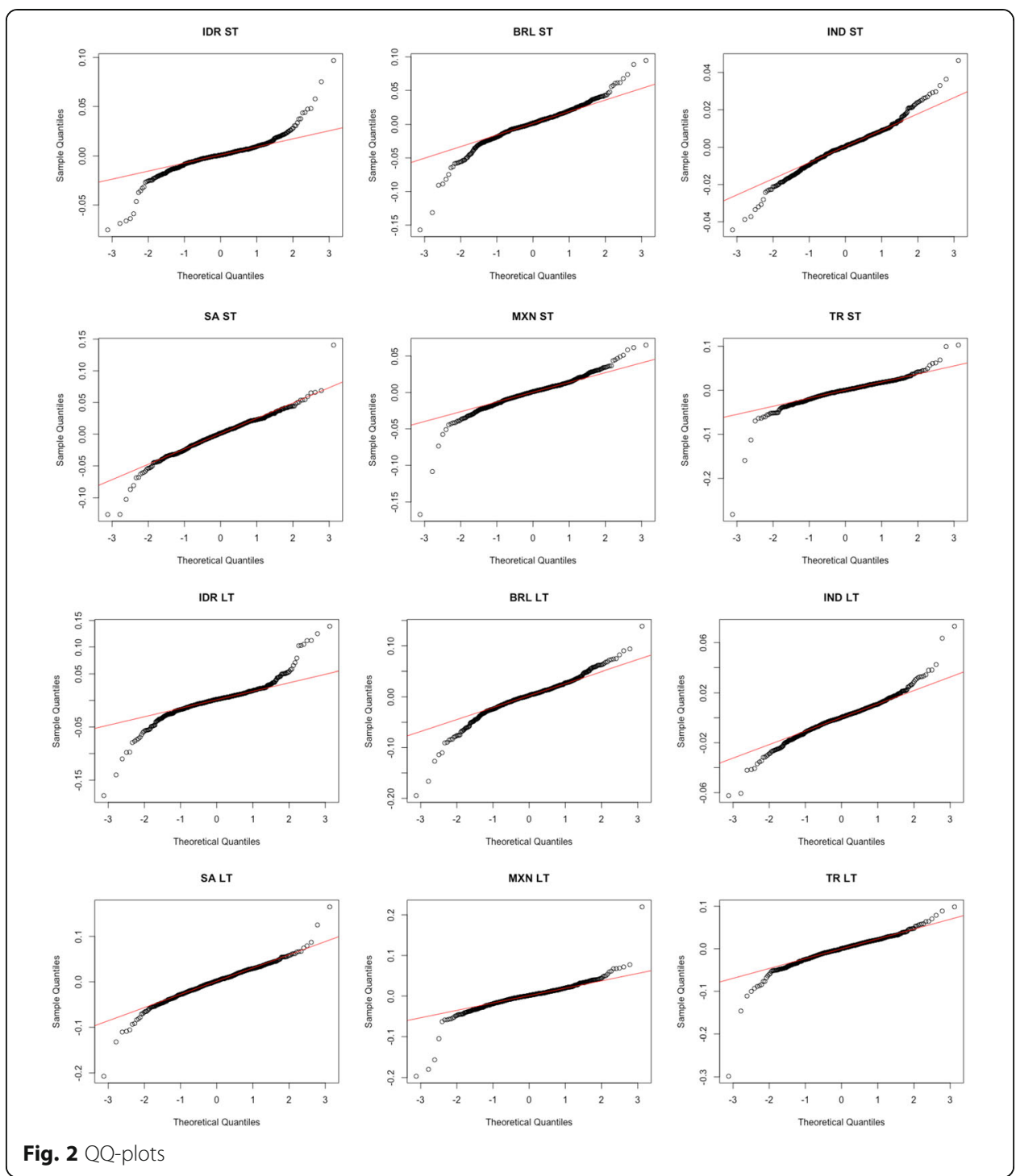

\section{Abbreviations}

BEKK: Baba, Engle, Kraft and Kroner; CAD: Current Account Deficit; DCC: Dynamic Conditional Correlation;

DM: Developed Market; EM: Emerging Market; FIAPARCH: Fractionally Integrated Asymmetric Power Autoregressional Conditional Heteroscedasticity; Fed: Federal Reserve; FIEGARCH: Fractionally Integrated Exponential Generalized Autoregressional Conditional Heteroscedasticity; FIGARCH: Fractionally Integrated Generalized Autoregressional Conditional Heteroscedasticity; GARCH: Generalized Autoregressional Conditional Heteroscedasticity; GDP: Gross Domestic Product; HYGARCH: Hyperbolic Generalized Autoregressional Conditional Heteroscedasticity; LM: Lagrange Multiplier; LT: Long Term Bonds; MIDAS: Mixed-Data Sampling; OECD: Organisation for Economic Co-operation and Development; OLS: Ordinary Least Squares; SHIBOR: Shangai Interbank Overnight Interest Rate; ST: Short Term Bonds

\section{Authors' contributions}

The author M.D. structured the data, performed the analytical calculations, interpreted the results, and wrote the manuscript. The author G.U. conceived the main concept, supervised the study and, contributed to the interpretations. Both authors contributed to the final version of the manuscript. The author(s) read and approved the final manuscript.

\section{Funding}

Not applicable.

\section{Availability of data and materials}

All data are gathered via individual data channels such as Bloomberg, Reuters, and Rasyonet. The models and data analysis are applied through computer software such as MS Excel, R, and Oxmetrics. All data and materials are available upon request. 


\section{Competing interests}

The authors declare that they have no competing interests.

\section{Author details}

${ }^{1}$ Treasury Department, Isbank AG, 60313 Frankfurt am Main, Germany. ${ }^{2}$ Financial Economics Department, Yeditepe University, 34755 Istanbul, Turkey. ${ }^{3}$ Administrative Sciences, Bahcesehir University, 34349 Istanbul, Turkey.

Received: 3 May 2019 Accepted: 9 September 2020

Published online: 03 December 2020

\section{References}

Baillie R (1996) Long memory processes and fractional integration in econometrics. J Econ 73(1):5-59

Baillie R, Morana C (2007) Modeling long memory and structural breaks in conditional variances: an adaptive FIGARCH approach. Working Papers from Queen Mary University of London 593

Bekiros SD, Hammoudeh S, Jammazi R, Nguyen DK (2018) Sovereign bond market dependencies and crisis transmission around the Eurozone debt crisis : a dynamic copula approach. Appl Econ 50-47:5029-5047

Benlagha N (2014) Dependence structure between nominal and index-linked bond returns: a bivariate copula and DCCGARCH approach. Appl Econ 46(31):3849-3860

Bessler W, Leonhardt A, Wolff D (2016) Analyzing hedging strategies for fixed income portfolios: a Bayesian approach for model selection. Int Rev Financ Anal 46:239-256

Bhuiyan RA, Rahman MP, Saiti B, Ghani GM (2018) Financial integration between sukuk and bond indices of emerging markets: insights from wavelet coherence and multivariate-GARCH analysis. Borsa Istanbul Rev 18-3:218-230

Bollerslev T (1986) Generalized autoregressive conditional heteroskedasticity. J Econ 31-3:307-327

Bollerslev T (1990) Modelling the coherence in short-run nominal exchange rates: a multivariate generalized ARCH model. Rev Econ Stat 72(3):498-505

Box G, Jenkins G (1976) Time series analysis: forecasting and control, Holden-Day

Burik P, Ennis R (1990) Foreign bonds in diversified portfolios: a limited advantage. Financ Anal J 46:31-40

Celik S (2012) The more contagion effect on emerging markets: the evidence of DCC-GARCH model. Econ Model 29-5:1946-1959

Champagne C, Coggins F, Sodjahin A (2017) Corporate bond market interdependence: credit spread correlation between and within US and Canadian corporate bond markets. N Am J Econ Financ 41:1-17

Chang C, Mcaleer M, Tansuchat R (2012) Modelling long memory volatility in agricultural commodity futures returns. Ann Financ Econ 7-2:1-27

Chao W, Zou H (2018) Multiple-event catastrophe bond pricing based on CIR-copula-POT model. Discret Dyn Nat Soc:1-9

Chen XB, Silvapulle P, Silvapulle M (2014) A semiparametric approach to value-at-risk, expected shortfall and optimum asset allocation in stock-bond portfolios. Econ Model 42:230-242

Christiansen C (2010) Decomposing European bond and equity volatility. Int J Financ Econ 15:105-122

Christoffersen P (1998) Evaluating interval forecasts. Int Econ Rev 39(4):841-862

Cotter J (2004) Uncovering long memory in high frequency UK futures. Eur J Financ 11 https://doi.org/10.2139/ssrn.998493

Dimitriou D, Kenourgios D, Simos T (2013) Global financial crisis and emerging stock market contagion: a multivariate FIAPARCH-DCC approach. Int Rev Financ Anal 30:46-56

Dimpfl T, Peter FJ (2016) Price discovery in the markets for credit risk: a Markov switching approach. Stud Nonlinear Dynamics Econ 20-3:233-249

Ding Z, Granger C, Engle R (1993) "Modelling long memory volatility in agricultural commodity futures", econometric institute Erasmus University, No El 2012-15

Elliott RJ, Nishide K (2014) Pricing of discount bonds with a Markov switching regime. Ann Finance 10:509-522

Engle R (1982) Autoregressive conditional heteroscedasticity with estimates of the variance of United Kingdom inflation. Econometrica 50-4:987-1007

Engle R (2002) Dynamic conditional correlation. J Bus Econ Stat 20-3:339-350 https://doi.org/10.1198/073500102288618487

Engle R, Colacito R (2006) Testing and valuing dynamic correlations for asset allocation. J Bus Econ Stat 24:238-253

Engle R, Sheppard K (2001) Theoretical and empirical properties of dynamic conditional correlation multivariate GARCH. Department of Economics, UC San Diego, University of California at San Diego, Economics Working Paper Series

Erb C, Harvey C, Viskanta E (1999) Understanding emerging market bonds. Emerg Mark Q 1:1-17

Escobar M, Neykova D, Zagst R (2017) HARA utility maximization in a Markov-switching bond-stock market. Quant Finance 17-11:1715-1733

Fang L, Chen B, Yu H, Xiong C (2018) The effect of economic policy uncertainty on the long-run correlation between crude oil and the U.S. stock markets. Financ Res Lett 24:56-63

Ferreira P (2018) Efficiency or speculation? A time-varying analysis of European sovereign debt. Phys A Stat Mech Appl 490: $1295-1308$

Goeij P (2004) Modeling the conditional covariance between stock and bond returns: a multivariate GARCH approach. J Financ Econ 2:531-564

Granger CWJ, Joyeux R (1980) An introduction to long memory time series models and fractional differencing. J Time Ser Anal 1:15-30

Guidolin M, Hyde S, McMillan D, Ono S (2014) Does the macroeconomy predict UK asset returns in a nonlinear fashion? Comprehensive out-of-sample evidence. Oxf Bull Econ Stat 76-4:510-535

Gulerce M, Unal G (2016) Using wavelet analysis to uncover the co-movement behavior of multiple energy commodity prices. Int J Wavelets Multiresolution Inf Process 14:1650047 https://doi.org/10.1142/S0219691316500478

Guo H, Wu G, Xiao Z (2007) An analysis of risk for defaultable bond portfolios. J Risk Financ 8-2:166-185

Harris R, Nguyen A (2013) Long memory conditional volatility and asset allocation. Int J Forecast 29(2):258-273

Hevia C, Gonzalez RM, Sola M, Spagnolo F (2015) Estimating and forecasting the yield curve using a Markov switching dynamic Nelson and Siegel model. J Appl Econ 30-6:987

Hosking JRM (1980) The multivariate portmanteau statistic. J Am Stat Assoc 75(371):602-608 
Hosking JRM (1981) Fractional differencing. Biometrika 68-1:165-176

Jin HJ, Frechette DL (2004) Fractional integration in agricultural futures price volatilities. Am J Agric Econ 86(2):432-443

Jung JW, Kim K (2012) Return volatilities of the Korea treasury bond in financial markets. J Korean Phys Soc 60:637

Kasman A (2009) Estimating value-at-risk for the Turkish stock index futures in the presence of long memory volatility. Cent Bank Rev 1:1-14

Kenourgios D, Christopoulos A, Dimitriou D (2013) Asset markets contagion during the global financial crisis. Multinatl Finance J 17-1(2):49-76

Kenourgios D, Padhi P (2012) Emerging markets and financial crises: regional, global or isolated shocks? J Multinatl Financ Manag 22:24-38

Kenourgios D, Samitas A, Paltalidis N (2011) Financial crises and stock market contagion in a multivariate time-varying asymmetric framework. J Int Financ Mark Inst Money 21-1:92-106

Kim JM, Dong H, Kim HJ (2020) Modeling non-normal corporate bond yield spreads by copula. North Am J Econ Finance 53:1-15

Kim S, Kim S-Y, Choi K (2019) Modeling and analysis for stock return movements along with exchange rates and interest rates in Markov regime-switching models. Cluster Comput J Netw Softw Tools Appl 22-1:2039

Kou G, Chao X, Peng Y, Alsaadi FE, Herrera-Viedma E (2019) Machine learning methods for systemic risk analysis in financial sectors. Technol Econ Dev Econ 25-5:716-742

Ksaier A, Cristiani-D'ornano I (2010) Interdependance and forecasting of S\&P500, oil, EURO / DOLLAR and 10-YEAR U.S. interest rate markets: an attempt of modelling through the volatility. Rev Econ Bus Stud 6:145-166

Kupiec P (1995) Techniques for verifying the accuracy of risk measurement models. J Derivatives 3:73-84

Lardic S, Mignon V (1999) Prévision ARFIMA des taux de change: les modélisateurs doivent-ils encore exhorter à la naïveté des prévisions? Ann Econ Stat 54:47-68 https://EconPapers.repec.org/RePEc:adr:anecst:y:1999:i:54:p:47-68

Manap TAA, Kassim SH (2011) Long memory properties and asymmetric effects of emerging equity market. J Risk Financ 125:356-370

Mandelbrot BB (1977) Fractals: form, chance, and dimension. W. H. Freeman and Company, San Francisco

Markowitz HM (1952) Portfolio selection. J Financ 7-1:77-91

Martinez LB, Guercio MB, Bariviera AF (2016) The impact of the financial crisis on the long-range memory of European corporate bond and stock markets. Empirica 45:1

McLeod Al, Li WK (1983) Diagnostic checking ARMA time series models using squared-residual autocorrelations. J Time Ser Anal 4(4):269-273

Mendoza VA (2005) Modelling long memory and risk Premia in Latin American sovereign bond markets. Dyn Model Their Appl Emerg Markets:41-68

Najeeb SF, Bacha O, Masih M (2017) Does a held-to-maturity strategy impede effective portfolio diversification for Islamic bond (Sukuk) portfolios? A multi-scale continuous wavelet correlation analysis. Emerg Mark Financ Trade 53-10:2377-2393

Narayan PK, Ahmed HA, Narayan S (2015) Do momentum-based trading strategies work in the commodity futures markets? J Futur Mark 35-9:868-891

Narayan PK, Sharma SS (2015) Does data frequency matter for the impact of forward premium on spot exchange rate? Int Rev Financ Anal 39:45-53

Ortobelli SP, Sebastiano F (2018) Price and market risk reduction for bond portfolio selection in BRICS markets. Investment Manage Financ Innov 15:120-131

Otani Y, Imai J (2018) An empirical analysis of the dependence structure of international equity and bond markets using regime-switching copula model. Int J Appl Math 48-2:191-205

Sclip A, Dreassi A, Miani S, Paltrinieri A (2016) Dynamic correlations and volatility linkages between stocks and sukuk: evidence from international markets. Rev Financ Econ:31-44

Selmi N, Hachicha N (2015) Multivariate FIGARCH and long memory process: evidence of oil price markets. Manage Sci Lett 5:873-882

Sensoy A, Sobaci C (2014) Effects of volatility shocks on the dynamic linkages between exchange rate, interest rate and the stock market: the case of Turkey. Econ Model 43-C:448-457

Serletis A, Andreadis I (2004) Random fractal structures in north American energy markets. Energy Econ 26-3:389-399

Tabak B, Cajueiro D (2007) Are the crude oil markets becoming weakly efficient over time? A test for time-varying long-range dependence in prices and volatility. Energy Econ 29-1:28-36

Tsukuda Y, Shimada J, Miyakoshi T (2017) Bond market integration in East Asia: multivariate GARCH with dynamic conditional correlations approach. Int Rev Econ Financ 51(C):193-213

Tsung PW, Shieh JS (2007) Value-at-risk analysis for long-term interest rate futures: fat-tail and long memory in return innovations. J Empir Financ 14-2:248-259

$\mathrm{Tu} \mathrm{AH}$, Chen CY (2018) A factor-based approach of bond portfolio value-at-risk: the informational roles of macroeconomic and financial stress factors. J Empir Financ 45:243-268

Vlaar PJG (2000) Value at risk models for Dutch bond portfolios. J Bank Financ 24-7:1131-1154

Wang H, Kou G, Peng Y (2020) Multi-class misclassification cost matrix for credit ratings in peer-to-peer lending. J Oper Res Soc https://doi.org/10.1080/01605682.2019.1705193

Wang KM (2013) Interest rate pass-through and illiquidity shocks in the US. J Econ Policy Reform 16(2):198-217

Weiß GNF (2013) Copula-GARCH versus dynamic conditional correlation: an empirical study on VaR and ES forecasting accuracy. Rev Quant Finan Acc 41-2:179

Wen F, Xu L, Ouyang G, Kou G (2019) Retail investor attention and stock price crash risk: evidence from China. Int Rev Financ Anal 65:101376

Yang L, Yang L, Ho KC, Hamori S (2020) Dependence structures and risk spillover in China's credit bond market: a copula and CoVaR approach. J Asian Econ 68

Zunino L, Bariviera AF, Guercio MB, Martinez LB, Rosso OA (2015) On the efficiency of sovereign bond markets. Phys A Stat Mech Appl 391-18:4342-4349

\section{Publisher's Note}

Springer Nature remains neutral with regard to jurisdictional claims in published maps and institutional affiliations. 